\title{
Upregulation of RBM24 Exacerbates Bladder Cancer Progression by Formatting Runx1t1/TCF4/miR-625-5p Feedback Loop
}

\section{Yue-Wei Yin}

Second Hospital of Hebei Medical University

Kai-Long Liu

Second Hospital of Hebei Medical University

\section{Bao-Sai Lu}

Second Hospital of Hebei Medical University

Wei Li

Second Hospital of Hebei Medical University

\section{Ya-Lin Niu}

Second Hospital of Hebei Medical University

\section{Chen-Ming Zhao}

The Second Hospital of Hebei Medical University

\section{Zhan Yang}

The Second Hospital of Hebei Medical University

\section{Ping-Ying Guo ( $\sim$ guopingying1@sina.com )}

Second Hospital of Hebei Medical University

Jin-Chun Qi

The Second Hospital of Hebei Medical University

\section{Research}

Keywords: RNA binding motif protein 24, Runx1t1, TCF4, proliferation, bladder cancer

Posted Date: July 27th, 2020

DOI: https://doi.org/10.21203/rs.3.rs-45346/v1

License: (c) (i) This work is licensed under a Creative Commons Attribution 4.0 International License. Read Full License 


\section{Abstract}

Background: RNA-binding motif protein 24 (RBM24) acts as a multifunctional determinant of cell fate, proliferation, apoptosis, and differentiation during development through regulation of pre-mRNA splicing and mRNA stability. It is also implicated in carcinogenesis, but the functions of RBM24 in bladder cancer (BC) remains unclear.

Methods: Cell viability was examined by colony forming and MTT assays. Real-time quantitative PCR (RT-qPCR) and western blot analysis were used to detect the protein and mRNA levels. Co-immunoprecipitation (CoIP) and proximity ligation assay (PLA) were used to determine the protein-protein interaction. Chromatin immunoprecipitation (ChIP), RNA immunoprecipitation (RIP), and oligo pull-down assays were used to verify DNA/RNA-protein interactions. Luciferase assay analysis was used to detect effects on transcription factor activity.

Results: In the present study, we revealed that RBM24 was upregulated in BC tissues. Importantly, we found that higher level of RBM24 was correlated with poor prognosis in BC patients. Overexpression of RBM24 promoted while depletion of RBM24 inhibited BC cell proliferation in vivo and in vitro. Mechanically, RBM24 positively regulated Runx1t1 expression in BC cells by binding to and enhancing Runx1t1 mRNA stability. Runx1t1 in turn promoted RBM24 expression by interacting with TCF4. Furthermore, Runx1t1 in turn promoted RBM24 expression by interacting with the transcription factor TCF4 and depressing transcription of miR-625-5p, which directly targets and normally suppresses RBM24 expression. RBM24-regulated BC cells proliferation was moderated via the Runx1t1/TCF4/miR-625-5p feedback loop.

Conclusions: In summary, these results indicate that a RBM24/Runx1t1/TCF4/miR-625-5p positive feedback loop plays a key role in $\mathrm{BC}$ oncogenesis. Disruption of this pathway may be a potential therapeutic strategy for $\mathrm{BC}$ treatment.

\section{Background}

Bladder cancer $(\mathrm{BC})$ is one of the most common malignancies in the urinary system with an estimated 450,000 new cases per year worldwide[1]. Among these cases, approximately $70 \%$ of new cases are non-muscle invasive (NMIBC) while 30\% are muscle invasive (MIBC)[2]. Surgery, chemotherapy, and radiation therapy are the mainly treatments for BC patients[3]. However, the 5-year survival rate of high-risk patients is still very low, and the current main treatment methods cannot prevent the recurrence or progression of these $\mathrm{BC}$ patients [4]. One important reason is the poor understanding of the mechanisms underlying BC development and progression. Therefrom, it is necessary for a better knowledge of the molecular basis of BC and exploration of innovative therapeutic strategies.

RNA-binding motif protein 24 (RBM24) is a multifunctional protein involved in regulation of pre-mRNA splicing, mRNA stability, and translation, and through these functions it acts as a critical determinant of cell fate and differentiation[5]. It was once believed that RBM24 is preferentially expressed in cardiac and skeletal muscle tissues and primarily serves to regulate embryonic heart development [6, 7]. However, recent studies have demonstrated that RBM24 also regulates cancer progression[8]. Hua et al found that RBM24 inhibited the 
progression of nasopharyngeal carcinoma by upregulating miR-25, which in turn downregulates MALAT1[9]. Using immunoprecipitation coupled to reverse transcription and microarray analysis (RIP-ChIP), Yu et al demonstrated that RBM24 is a multi-tasking RNA-binding protein (RBP) capable of regulating the stability and expression of multiple bound targets[10]. These RBPs may function as suppressors or facilitators of disease depending on the specific upstream regulators and downstream effectors (targets)[3]. However, the role RBM24 in $\mathrm{BC}$ is still unclear.

Runt-related transcription factor 1 (Runx1t1), is a member of Eight-Twenty-One (ETO) family proteins [11], Run1t1 was first identified through its involvement in a $t(8 ; 21)$ translocation associated with acute myeloid leukemia (AML) [12]. Subsequent studies reported that Runx1t1 acts as a transcriptional co-repressor by interacting with DNA-bound transcription factors and recruiting other proteins to facilitate transcriptional repression [13]. A recent study found upregulated expression of Runx $1 \mathrm{t} 1$ in cord blood-derived endothelial colony-forming cells[14]. In accord with functions in vascular endothelial development, a Runx1t1 deficient mouse showed reduced angiogenesis[15]. however, Runx1t1 was also reported to suppress colorectal cancer through regulation of cell proliferation and chemotherapeutic drug resistance [16]. and to upregulate the cell cycle genes Cdk4 and Cdk6 by recruiting a histone deacetylase (HDAC)-containing nuclear co-repressor complex[17, 18]. But the role of Runx1t1 in $\mathrm{BC}$ remains still unclear.

In the present study, we found that the higher RBM24 and Runx1t1 levels in BC tissue which were correlated with poor patient survival in BC patients. Moreover, overexpression of RBM24 upregulated Runx1t1 by stabilizing Runx1t1 mRNA and concomitantly accelerated BC proliferation. We identified a protein-protein interaction between Runx1t1 and TCF4 that suppresses miR-625-5p in transcriptional level, which play as negative regulator of RBM24 by directly targeting RBM24. Taken together, our results indicate that RBM24, Runx1t1, TCF4, and miR$625-5 p$ form a positive feedback loop that can drive the proliferation of $B C$ cells. The RBM24/Runx1t1/TCF4/miR-625-5p pathway may be a potential therapeutic target for BC treatment.

\section{Results}

\section{RBM24 is upregulated in BC tissues and contributes to poor prognosis.}

Our previous study has revealed that RBM5 is downregulated in BC tissue[3]. In contrast, mRNA and protein levels of RBM24 were frequently increased in BC tissue $(T)$ samples compared to normal bladder tissues $(N)$ as revealed by RT-qPCR and western blot analysis of 62 BC specimens (Fig. 1A and B). Similar results were obtained by immunofluorescence staining with a RBM24-specific antibody in a cohort of $161 \mathrm{BC}$ specimens (Fig. 1C and D), and correlation analysis showed that the mRNA level of RBM24 was significantly associated with tumor size and stage, but not with other clinicopathologic factors such as age, sex, and tumor grade (Table 1). Additionally, the TCGA database also revealed that higher RBM24 mRNA levels in BC patients were associated with poor overall survival $(P=0.00215$, Fig. $1 E)$. Together, these clinical data suggest that upregulation of RBM24 may be a critical event driving $\mathrm{BC}$ progression. 
Table 1

Correlation between RBM24 mRNA expression and clinicopathological characteristics

\begin{tabular}{|c|c|c|c|c|}
\hline \multirow[t]{2}{*}{ Characteristics } & \multirow[t]{2}{*}{ Number of patients (\%) } & \multicolumn{2}{|c|}{ RBM24 expression } & \multirow[t]{2}{*}{$P$ value ${ }^{a}$} \\
\hline & & Low (\%) & High (\%) & \\
\hline Total no. of patients & 161 & 89 & 72 & \\
\hline \multicolumn{5}{|l|}{ Age (years) } \\
\hline$\leq 63^{b}$ & 70 & $37(52.86)$ & $33(47.14)$ & \multirow[t]{2}{*}{0.772} \\
\hline$>63$ & 91 & $46(50.55)$ & $45(49.45)$ & \\
\hline \multicolumn{5}{|l|}{ Gender } \\
\hline Male & 102 & $56(54.90)$ & $46(45.10)$ & \multirow[t]{2}{*}{0.264} \\
\hline Female & 59 & $27(45.76)$ & $32(54.24)$ & \\
\hline \multicolumn{5}{|l|}{ Tumor size (cm) } \\
\hline$\leq 3.0^{c}$ & 106 & $58(54.72)$ & $48(45.28)$ & \multirow[t]{2}{*}{0.001} \\
\hline$>3.0$ & 55 & $15(27.27)$ & $40(72.73)$ & \\
\hline \multicolumn{5}{|l|}{ Tumor grade } \\
\hline Low & 97 & 45 (46.39) & $52(53.61)$ & \multirow[t]{2}{*}{0.221} \\
\hline High & 64 & $36(56.25)$ & $28(43.75)$ & \\
\hline \multicolumn{5}{|l|}{ T classification } \\
\hline $\mathrm{Ta}, \mathrm{T} 1$ & 105 & $46(43.81)$ & 59 (56.19) & \multirow[t]{2}{*}{0.041} \\
\hline T2-T4 & 56 & $34(60.71)$ & 22 (39.29) & \\
\hline \multicolumn{5}{|l|}{ pN status } \\
\hline $\mathrm{pN}-$ & 114 & $55(48.25)$ & $59(51.75)$ & \multirow[t]{2}{*}{0.120} \\
\hline $\mathrm{pN}+$ & 47 & $29(61.70)$ & $18(38.30)$ & \\
\hline \multicolumn{5}{|l|}{ Tumor multiplicity } \\
\hline Unifocal & 69 & $28(40.58)$ & $41(59.42)$ & \multirow[t]{2}{*}{0.818} \\
\hline Multifocal & 92 & 39 (42.39) & $53(57.61)$ & \\
\hline \multicolumn{5}{|c|}{ Significant associations are shown in bold face in the $p$ value column ( $p$ value $<0.05$ ) } \\
\hline \multicolumn{5}{|l|}{${ }^{\mathrm{a}}$ Chi-square test } \\
\hline \multicolumn{5}{|l|}{ bMedian age } \\
\hline${ }^{\mathrm{C}}$ Median size & & & & \\
\hline
\end{tabular}




\section{RBM24 promotes the proliferation of $\mathrm{BC}$ cells in vitro}

To investigate specific functions of RBM24 in BC, we first compared protein levels between a normal bladder cell line (SV-HUC-1) and a series of BC cell lines (UM-UC-3, 253J, T24, and J82). RBM24 was significantly elevated in two tumor cell lines (UM-UC-3 and 253J) but downregulated in one (J82 cells) compared to the normal bladder cells (Fig. 2A). However, mRNA expression of RBM24 was upregulated only in the $253 \mathrm{~J}$ cell line and decreased in J82 cell line (Fig. 2B). Therefore, these two cell lines were selected for subsequent loss- and gain-of-function experiments. In light of the correlation between RBM24 expression and tumor stage, we speculated that RBM24 may be involved in cell proliferation. Indeed, RBM24 knockdown in 253 J cells using a specific shRNA decreased while overexpression in J82 cells by transfection with a pWPI-RBM24 vector increased RBM24 expression compared to a shRNA control vector and empty overexpression vector, respectively(Fig. 2C). In addition, RBM24 knockdown in 253J cells suppressed expression of the cell proliferation marker CDK4 while overexpression in J82 cells increased CDK4 expression(Fig. 2C). Further, MTT and colony formation assays revealed that overexpression of RBM24 promoted J82 cell proliferation, while RBM24 knockdown restrained the proliferation of 253 J cells (Fig. 2D and E). Together, these data suggest that RBM24 promotes BC cell proliferation.

\section{Runx1t1 mediates the RBM24-induced cell proliferation}

Previous studies have reported that RBM24 functions as a regulator in multiple genes linked to cell proliferation, fate, differentiation, and apoptosis[10]. To investigate the molecular mechanisms underlying regulation of $\mathrm{BC}$ cell proliferation by RBM24, we examined the expression levels of candidate effectors selected according to previous studies[10]. Among 6 candidate genes, Runx1t1 was significantly downregulated in RBM24-depleted 253J cells and upregulated in RBM24-overexpressing J82 cells as revealed by western blot (Fig. 3A). Runx1t1 mRNA levels were also significantly upregulated in BC tissue samples compared to normal bladder tissues as measured by RTqPCR (Fig. 3B), as were Runx1t1 protein levels according to western blot and immunofluorescence staining (Fig. 3C and 3D). Moreover, human clinical data from the TCGA database of Oncolnc revealed that higher Runx1t1 expression was associated with poor prognosis $(P=0.0064$, Fig. $3 E)$. Additionally, correlation analysis showed that RBM24 mRNA expression was positively correlated with Runx1t1 mRNA expression in BC tissue (Fig. 3F).

To examine whether Runx1t1 contributes to RBM24-regulated BC cell proliferation, we performed a rescue experiment. As shown in Fig. 3G, 253J cell growth was reduced markedly following knockdown of RBM24 and Runx $1 \mathrm{t} 1$ together compared to knockdown of either gene alone. Conversely, the enhanced proliferation observed in $\mathrm{J} 82$ cells overexpressing RBM 24 was abolished by co-transfection with shRunx $1 \mathrm{t} 1$ as evidenced by colony formation assay (Fig. $3 \mathrm{H}$ ). Together, these data suggest that Runx1t1 participates in RBM24-mediated regulation of $\mathrm{BC}$ cell proliferation.

\section{RBM24 promotes Runx1t1 expression by stabilizing its mRNA}

Because RBM24 and Runx1t1 were positively correlated in BC, we then investigated whether RBM24 regulates Runx1t1 expression in BC cells and the underlying mechanisms. RT-qPCR results showed that overexpression of RBM24 upregulated mRNA expression level of Runx1t1 while knockdown of RBM24 downregulated the mRNA expression level of Runx1t1 in BC cells(Fig. 1A). As previous studies have reported that RBM24 enhances RNA 
stability [10, 19], we investigated if elevated RBM24 prolongs Runx1t1 mRNA expression following blockade of new transcription using actinomycin D (ActD). Indeed, RBM24 knockdown in 253J cells accelerated whereas overexpression in $\mathrm{J} 82$ cells prolonged Runx1t1 mRNA expression, consistent with RBM24-mediated enhancement of Runx1t1 mRNA stability (Fig. 4B). To confirm this notion, we examined whether RBM24 binds to Runx1t1 mRNA using in vitro RNA pull-down and RNA-binding protein immunoprecipitation (RIP) assays. Coimmunoprecipitation confirmed that a RBM24 antibody effectively pulled down endogenous RBM24 protein (Fig. 4C), and PCR analysis of RIP products revealed the presence of STAT3 and Runx1t1 mRNA 3'-untranslated regions (3'UTRs), but not the 3'UTR of GAPDH (Fig. 4D). Consistent with this finding, a biotinylated Runx1t1 mRNA-3'UTR and positive control STAT3-mRNA probe pulled down RBM24 protein, while a GAPDH mRNA-3'UTR probe did not (Fig. 4E). These results suggest that RBM24 can bind to the Runx1t1 mRNA 3'UTR, thereby enhancing mRNA stability.

We then used western blot to determine whether Runx1t1 regulates the expression levels of genes associated with cell proliferation. Depletion of Runx1t1 in 253J cells reduced expression of the proliferation marker gene CDK4 while overexpression of Runx1t1 in J82 cells increased CDK4 protein level (Fig. 4F). While RBM24 protein expression was positive regulated by Runx1t1 protein expression, neither depletion of Runx1t1 in 253J cells nor overexpression in J82 cells altered RBM24 mRNA levels (Fig. 4G).

\section{Runx1t1 interacts with transcription factor TCF4 to mediate RBM24 upregulation and cell proliferation}

Runx1t1 functions as a transcription cofactor by interacting with various partner proteins [20, 21]. To identify the partner(s) involved in RMB24 regulation, we performed co-immunoprecipitation coupled with mass spectrometry (ColP-MS). Eight proteins were upregulated in RBM24-overexpressing BC cells, including the transcription factor TCF4 (Fig. 5A), and reciprocal immunoprecipitation showed a strong interaction between Runx1t1 and TCF4 in $\mathrm{BC}$ cells (Fig. 5B). Also, an in situ proximity ligation assay (PLA) confirmed direct binding between Runx $1 \mathrm{t} 1$ and TCF4 (Fig. 5C). In addition, TCF4 mRNA levels were significantly upregulated in BC tissues compared to normal bladder tissues (Fig. 5D) and positively correlated with Runx1t1 mRNA (Fig. 5E). Survival analysis from the TCGA database showed that higher expression of TCF4 was associated with poor prognosis (Fig. 5F).

To investigate whether TCF4 participates in a RBM24/Runx1t1 axis to regulate BC cell proliferation, we performed rescue experiments. Co-transfection of 253J cells with shTCF4 and shRunx1t1 inhibited expression of RBM24 and CDK4 to a greater extent that knockdown of Runx1t1 alone (Fig. 5G). Transfection of J82 cells with shTCF4 also sharply reduced RBM24 and CDK4 expression levels, and this reduction was reversed by cotransfection with Runx1t1 overexpression vector (Fig. 5H). Knockdown of TCF4 and Runx1t1 also decreased the proliferation rate of 253J cells to a greater extent than knockdown of either protein alone. Conversely, overexpression of Runx1t1 promoted J82 cell growth, an effect abolished by shTCF4 co-transfection (Fig. 5I). Since Runx1t1 alone did not regulate RBM24 transcription (Fig. 4G), we examined whether TCF4 regulates RBM24 transcription. However, neither Runx1t1 nor TCF4 regulated RBM24 mRNA expression (Fig. 5J). Together, these data suggest that Runx1t1 interacts with TCF4 to promote RBM24 protein expression rather than gene transcription. 


\section{miR-625-5p mediates Runx1t1/TCF4-regulated proliferation by direct targeting in $\mathrm{BC}$ cells}

Regulation of RMB24 protein expression by Runx1t1/TCF4 without influencing RBM24 mRNA level suggests that Runx1t1/TCF4 regulates RBM24 at the posttranscriptional level. MicroRNAs (miRNAs) are critical regulators of gene expression at the posttranscriptional level, so we conducted bioinformatics analyses using TargetScan, miRanda, and RNA22 to predicted miRNA sequences targeting the RBM24 3'-UTR and then used a T7 RNA transcriptase to generate a RBM24 3'-UTR containing biotin-labeled uracil (Fig. 6A). After transfection, complementary miRNAs were extracted by pull-down assay and the expression levels of 9 candidates compared by RT-PCR. The result showed that miR-149-3p, miR-216a-5p, miR-625-5p, miR-449a, and miR-578, were enriched by the RBM24 3'-UTR pull-down assay (Fig. 6B). Next, we assessed miRNA expression levels after up- and downregulation of Runx1t1 and TCF4 expression to identify the miRNAs involved in Runx1t1/TCF4-mediated regulation of RBM24 expression. As shown in Fig. 6C, only miR-625-5p was regulated by both Runx1t1 and TCF4. Furthermore, a luciferase reporter assay showed that miR-625-5p directly targeted RBM24 3'UTR (Fig. 6D and E) and western blot confirmed that RBM24 protein expression was reduced by miR-625-5p mimic transfection into BC cells compared to its antagomir (Fig. 6F). Notably, expression of miR-625-5p was downregulated in BC tissue compared to normal bladder tissues (Fig. 6G). Moreover, survival analysis from the TCGA database revealed that lower expression of miR-625-5p was associated with poor prognosis (Fig. 6H). Additionally, miR-625-5p expression was negatively correlated with RBM24 mRNA expression in BC tissue (Fig. 6I).

To investigate whether the Runx1t1/TCF4 complex regulates RBM24 expression by directly depressing miR-625$5 p$ transcription, we first predicted the potential TCF element within the 2-kb 5'-promoter region of miR-625-5p using Ensembl and PROMO 3.0 websites, which identified three potential TCF elements (Fig. 6J). ChIP analysis confirmed that Runx1t1/TCF4 bound predominantly to the region - 522 to - 532 bp upstream of the transcription start site within the miR-625-5p promoter (Fig. 6K), and a luciferase assay yielded similar results (Fig. 6L). Together, these findings indicate that Runx1t1/TCF4 directly inhibits the transcription of miR-625-5p, which in turn disinhibits RBM24 expression.

\section{Disruption of the RBM24/Runx1t1/TCF4/miR-625-5p axis inhibits $B C$ xenograft growth in vivo}

Finally, we examined whether RBM24 and Runx1t1 regulate BC cell growth in vivo using a xenograft model. Injection of 253J cells with stable knockdown of RBM24 and Runx1t1 yielded smaller tumors in nude mice than injection of sham-transfected $253 \mathrm{~J}$ cells. Furthermore, the tumor volume was much smaller in mice implanted with RMB25/Runx11 double knockdown cells compared to single knockdown cells (Figs. 7A and B). These findings were mirrored by mean tumor wet weights following excision (Fig. 7C). Western blot analysis of extracted tumor tissue also demonstrated that silencing of either Runx1t1 or RBM24 significantly downregulated Runx1t1, RBM24, and CDK4 compared to tumors derived from control cells, and this downregulation was further enhanced by simultaneous knockdown of both Runx1t1 and RBM24 (Fig. 7D). These findings suggest RBM24/Runx1t1/TCF4/miR-625-5p axis inhibits cell proliferation in BC cells in vivo. Figure 8 shows our proposed model illustrating the role of the RBM24/Runx1t1/TCF4/miR-625-5p feedback loop in BC. 


\section{Discussion}

In this study, we identified a RBM24/Runx1t1/TCF4/miR-625-5p feedback loop that drives BC oncogenesis. First, RBM24 expression was significantly higher in BC tissues than corresponding normal tissues, and elevated RBM24 expression was correlated with poor prognosis. Second, RBM24 overexpression promoted BC cell proliferation in vivo and in vitro, and enhanced Runx1t1 protein expression by increasing Runx1t1 mRNA stability. Third, Runx1t1 interacted with the transcription factor TCF4, and this Runx1t1-TCF4 complex positively regulated RBM24 protein expression by suppressing expression of the RBM24 negative regulator miR-625-5p, resulting in formation of a positive feedback loop driving elevated RBM24 expression and BC cell proliferation. These findings suggest that the RBM24/Runx1t1/TCF4/miR-625-5p axis is a critical promoter of BC initiation and progression.

RBPs influence the structure and interactions of target RNAs, thereby influencing RNA biogenesis, stability, function, transport, and subcellular localization[22]. Many RBPs are expressed in a tissue-specific manner to drive developmental processes [23]. For instance, RBM24 is highly expressed in heart and muscle tissues [7], and regulates cardiac embryonic stem cell differentiation by a splicing-mediated mechanism [24]. In addition, RBM24 was reported to suppress nasopharyngeal cancer progression [9]. In the current study, however, RBM24 accelerated BC cell proliferation both in vivo and in vitro. This discrepancy may be explained by differences in upstream and downstream regulatory factors [25]. Consistent with this accelerated proliferation, high levels of RBM24 promoted the expression of Runx1t1 and correlated with poor prognosis in BC patients.

Transcription factor 4 (TCF4) is a member of helix-loop-helix (bHLH) transcription factor family that recognize and bind the Ephrussi box (E-Box) DNA element (5'-ACANNTGT-3') [26]. TCF4 regulates chromatin remolding and transcription by recruiting histone acetyltransferases (HATs) such as p300 [27]. Numerous studies have also implicated TCF4 in cancer progression. Jagrut et al reported that TCF4 signaling was upregulated in colon cancer stem cells and promoted growth and self-renewal [28]. The expression of TCF4 is associated with breast cancer chemoresistance [29]. Additionally, high expression of TCF4 was an independent adverse prognostic factor in acute myeloid leukemia [30]. However, the expression and function of TCF4 in BC is largely unknown. In the present study, we found that TCF4 was upregulated in BC tissues and that high expression was predictive of poor prognosis. We demonstrated that interaction with Runx1t1 and subsequent downregulation of miR-625-5p, resulting in RBM24 upregulation, is one mechanism underlying the oncogenic effect of TCF4.

\section{Conclusion}

The present study demonstrates that upregulation of RBM24 enhances BC cell proliferation and leads to poor BC prognosis by initiating a Runx1t1/TCF4/miR-625-5p feedback loop. These findings highlight the RBM24/Runx1t1/TCF4/miR-625-5p axis as a potential therapeutic target for BC treatment.

\section{Methods}

\section{Clinical samples}

Human primary BC tissues and the corresponding normal bladder tissues were collected from the BC patients who were admitted to the Department of Urology of the Second Hospital of Hebei Medical University from July 
2015 to June 2019. All BC patients were histopathologically and clinically diagnosed and were treated with radical cystectomy. The study protocol was approved by the Ethics Committee of Second Hospital of Hebei Medical University and written consent was obtained from each patient.

\section{Cell lines and transfection}

Normal uroepithelial cell SV-HUC-1 was purchased from the Cell Bank of the Chinese Academy of Sciences and bladder cancer cell lines UM-UC-3, 253J,T24 and J82 were purchased from ATCC (Rockvill, Maryland) and 293A cell line collected in our lab, and all cells cultured in DMEM supplemented with 10\% Fetal Bovine Serum (FBS), 1\% penicillin/streptomycin. Cells were grown in a humidified atmosphere of $95 \%$ air and $5 \% \mathrm{CO} 2$. The transfection was performed according to the manufacturer's protocols by using Lipofectamine 2000 (Invitrogen). The miR625-5p, miR-149-3p and miR-449a mimics, mimic NC, miR-625-5p inhibitors, inhibitor NC, shRBM24, shRunx1t1, shTCF4 and negative controls were purchased from GenePharma Co., Ltd (Shanghai, China). The over-expression plasmids of oeRBM24, oeRunx1t1 was obtained from GENEWIZ Company (Suzhou, China) .

\section{RNA extraction and real time quantitative PCR}

Clinical tumor tissues and xenograft tissues were lysed using QIAzol Lysis Reagent (79306). Total RNA was isolated with a miRNeasy Mini Kit (217004; Qiagen) according to the manufacturer's protocols. NanoDrop 2000 was used to determine RNA quality. For miRNA, miScript II RT Kit (218161) and miScript SYBR Green PCR Kit (Catalog no. 218073) were used to reverse transcription and quantitative real-time (qRT)-PCR according to the manufacturer's protocol with following primers listed in Supplementary Table 2. For mRNA, cDNA was synthesized using a M-MLV First Strand Kit (Life Technologies) with random hexamer primers. mRNAs were subjected to qRT-PCR using the Platinum SYBR Green qPCR Super Mix UDG Kit (Invitrogen) and the ABI 7500 FAST system (Life Technologies) with primers listed in Table 2. Relative transcript expression levels were normalized to GAPDH and calculated using the $2^{-\Delta \Delta C t}$ formula as previously described(29). 
Table 2

Oligos used in the study

\begin{tabular}{|c|c|c|c|}
\hline $\begin{array}{l}\text { Oligo } \\
\text { name }\end{array}$ & Sequence $\left(5^{\prime}-3^{\prime}\right)$ & Purpose & $\begin{array}{l}\text { Amplicon } \\
\text { (bp) }\end{array}$ \\
\hline RBM24-F: & GCTGGATGCCGGTTGTTAAG & \multirow{2}{*}{$\begin{array}{l}\text { RT-qPCR for } \\
\text { RBM24 } \\
\text { mRNA. }\end{array}$} & \multirow[t]{2}{*}{357} \\
\hline RBM24-R: & GCACAAAAGCCTGCGGATAG & & \\
\hline TCF4-F & AGCAGAGTCTCCTTGGAGGT & \multirow{2}{*}{$\begin{array}{l}\text { RT-qPCR for } \\
\text { TCF4 } \\
\text { mRNA. }\end{array}$} & \multirow[t]{2}{*}{206} \\
\hline TCF4-R & AGTGCTTGCTGATGGAGCAT & & \\
\hline $\begin{array}{l}\text { RUNX1T1- } \\
\text { F }\end{array}$ & TCACACACAATGTGCCATCCT & \multirow[t]{2}{*}{$\begin{array}{l}\text { RT-PCR for } \\
\text { RUNX1T1 } \\
\text { mRNA. }\end{array}$} & \multirow[t]{2}{*}{273} \\
\hline $\begin{array}{l}\text { RUNX1T1- } \\
\text { R }\end{array}$ & TCGGTGAGTCCTGTCTGGAT & & \\
\hline GAPDH-F: & AAGGTGAAGGTCGGAGTCAAC & \multirow{2}{*}{$\begin{array}{l}\text { RT-qPCR for } \\
\text { GAPDH }\end{array}$} & \multirow[t]{2}{*}{102} \\
\hline GAPDH-R: & GGGGTCATTGATGGCAACAATA & & \\
\hline miR-29a-F & GGACTGATTTCTTTTGGTGTTCAG & $\begin{array}{l}\text { RT-qPCR for } \\
\text { miR-29a }\end{array}$ & $\mathrm{N} / \mathrm{A}$ \\
\hline $\begin{array}{l}\text { miR-138- } \\
\text { 3p-F }\end{array}$ & GCTACTTCACAACACCAGGGC & $\begin{array}{l}\text { RT-qPCR for } \\
\text { miR-138-3p }\end{array}$ & $\mathrm{N} / \mathrm{A}$ \\
\hline $\begin{array}{l}\text { miR-149- } \\
\text { 3p-F }\end{array}$ & AGGGAGGGACGGGGGCTG & $\begin{array}{l}\text { RT-qPCR for } \\
\text { miR-149-3p }\end{array}$ & $\mathrm{N} / \mathrm{A}$ \\
\hline $\begin{array}{l}\text { miR-216a- } \\
5 p-F\end{array}$ & GGTAATCTCAGCTGGCAACTGTG & $\begin{array}{l}\text { RT-qPCR for } \\
\text { miR-216a-5 }\end{array}$ & $\mathrm{N} / \mathrm{A}$ \\
\hline $\begin{array}{l}\operatorname{miR}-222- \\
5 p-F\end{array}$ & GGCCTCAGTAGCCAGTGTAGATC & $\begin{array}{l}\text { RT-qPCR for } \\
\text { miR-222-5p }\end{array}$ & $\mathrm{N} / \mathrm{A}$ \\
\hline $\begin{array}{l}\operatorname{miR}-625- \\
5 p-F\end{array}$ & GGCAGGGGGAAAGTTCTATAGTCC & $\begin{array}{l}\text { RT-qPCR for } \\
\text { miR-625-5p }\end{array}$ & $\mathrm{N} / \mathrm{A}$ \\
\hline $\begin{array}{l}\text { miR-449a- } \\
F\end{array}$ & GGTGGCAGTGTATTGTTAGCTGG & $\begin{array}{l}\text { RT-qPCR for } \\
\text { miR-449a }\end{array}$ & $\mathrm{N} / \mathrm{A}$ \\
\hline miR-578-F & GGCCTTCTTGTGCTCTAGGATTG & $\begin{array}{l}\text { RT-qPCR for } \\
\text { miR-578 }\end{array}$ & $\mathrm{N} / \mathrm{A}$ \\
\hline $\begin{array}{l}\text { miR-1273- } \\
\text { F }\end{array}$ & CGGGCGACAAAGCAAGACTC & $\begin{array}{l}\text { RT-qPCR for } \\
\text { miR-1273 }\end{array}$ & $\mathrm{N} / \mathrm{A}$ \\
\hline $\begin{array}{l}\text { RNU6- } \\
1 \text { (U6)-F }\end{array}$ & GTGCTCGCTTCGGCAGCACATATAC & \multirow[t]{2}{*}{$\begin{array}{l}\text { RT-qPCR for } \\
\text { the internal } \\
\text { control U6 }\end{array}$} & \multirow[t]{2}{*}{106} \\
\hline $\begin{array}{l}\text { RNU6- } \\
1 \text { (U6)-R }\end{array}$ & AAAATATGGAACGCTTCACGAATTTGC & & \\
\hline $\begin{array}{l}\text { miR-625- } \\
\text { ChIP-1-F:: }\end{array}$ & TGGCTCCGCCCCCTTTCAG & \multirow[t]{2}{*}{$\begin{array}{l}\text { ChIP-PCR } \\
\text { for miR-625- } \\
5 p \text { promoter. }\end{array}$} & \multirow[t]{2}{*}{176} \\
\hline $\begin{array}{l}\text { miR-625- } \\
\text { ChIP-1-R: }\end{array}$ & GACTGCTGAGCCTGCCACTCC & & \\
\hline
\end{tabular}




\begin{tabular}{|c|c|c|c|}
\hline $\begin{array}{l}\text { Oligo } \\
\text { name }\end{array}$ & Sequence $\left(5^{\prime}-3^{\prime}\right)$ & Purpose & $\begin{array}{l}\text { Amplicon } \\
\text { (bp) }\end{array}$ \\
\hline $\begin{array}{l}\text { miR-625- } \\
\text { ChIP-2-F:: }\end{array}$ & GAAGTGGCAGCGGGAACAGG & \multirow{2}{*}{$\begin{array}{l}\text { ChIP-PCR } \\
\text { for miR-625- } \\
5 p \text { promoter. }\end{array}$} & \multirow[t]{2}{*}{225} \\
\hline $\begin{array}{l}\text { miR-625- } \\
\text { ChIP-2-R: }\end{array}$ & CCAGGAGCAGGCAGCAGCC & & \\
\hline $\begin{array}{l}\text { miR-625- } \\
\text { ChIP-3-F:: }\end{array}$ & CCCAGGAGCCTGTCTGCTTCC & \multirow{2}{*}{$\begin{array}{l}\text { ChIP-PCR } \\
\text { for miR-625- } \\
5 p \text { promoter. }\end{array}$} & \multirow[t]{2}{*}{167} \\
\hline $\begin{array}{l}\text { miR-625- } \\
\text { ChlP-3-R: }\end{array}$ & GGATATCATCACAGCCCAACAGG & & \\
\hline $\begin{array}{l}\text { RBM24- } \\
\text { 3'UTR-F: }\end{array}$ & CTCGAGACCAGCCATCTGATCAAAGTTG & \multirow{2}{*}{$\begin{array}{l}\text { PCR } \\
\text { amplified } \\
\text { RBM24 } \\
\text { 3'UTR for } \\
\text { clone. }\end{array}$} & \multirow[t]{2}{*}{1756} \\
\hline $\begin{array}{l}\text { RBM24- } \\
\text { 3'UTR-R: }\end{array}$ & GAATTCGAAGTTTTTAAAAAATTATATTTAATAC & & \\
\hline $\begin{array}{l}\text { RBM24- } \\
\text { 3'UTR-T7- } \\
\text { F: }\end{array}$ & GGATCCTAATACGACTCACTATAGGACCAGCCATCTGATCAAAGTTG & \multirow{2}{*}{$\begin{array}{l}\text { PCR } \\
\text { amplified } \\
\text { RBM24 } \\
3^{\prime} U T R \\
\text { sequence } \\
\text { for } \\
\text { transcription } \\
\text { in vitro. }\end{array}$} & \multirow[t]{2}{*}{1756} \\
\hline $\begin{array}{l}\text { RBM24- } \\
\text { 3'UTR-T7- } \\
\text { R: }\end{array}$ & GAATTCGAAGTTTTTAAAAAATTATATTTAATAC & & \\
\hline
\end{tabular}

\section{Biotin-labeled RNA synthesis and pull-down}

Biotin-labeled RNA was synthesized by in vitro transcription as previously described[3]. RBM24 3' UTR containing T7 promoter sequences were amplified with or without Biotin-16-UTP (Ambion, AM8452) by using MEGAscript T7 transcription kit (Ambion, AM1334). miRNeasy Mini Kit (217004; Qiagen) was purified transcribe RNA and biotin pull-down was carried out to detected RBM24 3' UTR and microRNAs interaction as previously described (30). In brief, cells were transfected with $4 \mu \mathrm{g}$ biotin-labeled RNA for $24 \mathrm{~h}$. And then cells were cross-linked with $1 \%$ formaldehyde in PBS, then quenched with $0.125 \mathrm{M}$ glycine. The cells were resuspended in lysis buffer on ice for $10 \mathrm{~min}$ and were sonicated. The cell lysate was diluted in two times volume with hybridization buffer.

Streptavidin Dynabeads (Life Technologies) were blocked for $2 \mathrm{~h}$ at $4{ }^{\circ} \mathrm{C}$ in lysis buffer containing $1 \mathrm{mg} / \mathrm{ml}$ yeast tRNA and $1 \mathrm{mg} / \mathrm{ml} \mathrm{BSA}$ and wash twice with $1 \mathrm{ml}$ lysis buffer. $100 \mu \mathrm{l}$ washed/blocked Dynabeads was added, and the whole mix was then rotated for $30 \mathrm{~min}$ at $37^{\circ} \mathrm{C}$. Beads were captured by magnets (Life Technologies) and washed five times. Beads were then subjected to RNA elution with buffer.

\section{Coimmunoprecipitation (ColP) assay}

$3 \mu \mathrm{g}$ of antibodies and protein A-agarose were added to $253 \mathrm{~J}$ cell lysates for $12 \mathrm{~h}$ at $4{ }^{\circ} \mathrm{C}$. Then protein Aagarose-antigen-antibody complexes were collected by centrifugation. After washed by IPH buffer, the extensive wash with lysis buffer, the immunoprecipitates were resolved by $10 \%$ SDS-PAGE, followed by Western blot analysis. 


\section{Proximity ligation assay}

The proximity ligation assay (PLA) was performed as described previously [31]. Briefly, 253J cells were seeded into 6 well chamber slides and cultured for 24 hours. Then $4 \%$ paraformaldehyde were used to fixate the sliders. anti-Runx1t1 and anti-TCF4 were used to stain the slides. Rabbit PLUS and Mouse MINUS Duolink in situ proximity ligation assay (PLA) kits were used to detect the interaction between the two proteins following the manufacturer's protocols. Fluorescence was detected using a laser scanning confocal microscope.

\section{Western blot analysis}

Western blot analysis was carried on as described previously[32]. The protein was extracted from the cultured cells and frozen tissue samples with RIPA lysis buffer. Equal amounts of protein were run on SDS-PAGE, and electro-transferred to a polyvinylidene fluoride (PVDF) membranes (Millipore) which blocked with $5 \%$ milk for $2 \mathrm{~h}$. Then membranes incubated with primary antibodies overnight at $4{ }^{\circ} \mathrm{C}$. The antibodies that were used were as follows: anti-RBM24 (1:500, 18178-1-AP), anti-STAT3 (1:1000, 10253-2-AP), anti-CDK4 (1:1000, 60186-1-Ig), antiIGF1R (1:500, 20254-1-AP), anti-Runx1t1 (1:1000, 15494-1-AP), anti-EGLN1 (1:500, 66589-1-Ig), anti-TCF4 (1:500,22337-1-AP), or anti- $\beta$-actin (1:1000, sc-47778). Membranes were then incubated with the HRP-conjugated secondary antibody (1:5000, Rockland) for $1 \mathrm{~h}$ at room temperature. The blots were treated with the ImmobiloTM Western (Millipore), and detected by ECL (enhanced chemiluminescence) Fuazon Fx (Vilber Lourmat). Images were captured and processed by FusionCapt Advance Fx5 software (Vilber Lourmat). All experiments were replicated three times.

\section{Vector construction and luciferase reporter assay}

The 3' untranslated region (UTR) sequences of RBM24 containing wild-type forms of the miR-625-5p target site were inserted into the Xho1 and EcoR1 digested-psiCHECK Vector (Promega Corp). $2 \mathrm{~kb}$ miR-625 promoter sequence was obtained by PCR with primer and inserted into the Mlu1 and Xho1 digested-pGL3-basic vector (Promega Corp., Madison, WI, USA). Luciferase assay was performed as described previously (32). In brief, 293A cells were seeded into a 24-well plate, RBM24 reporter construct (wild-type or mutant) or the empty reporter vector was co-transfected with miR-625-5p mimic and pRL-TK, or co-transfected with mimic control and pRL-TK, or 293A cells were co-transfected with pGL3-miR-luc vector or oeRBM24 or shTCF4 for $24 \mathrm{~h}$. Luciferase activity was measured by Dual-Glo Luciferase Assay System (Promega, Madison, WI) with a Flash and Glow (LB955, Berthold Technologies) reader. The specific target activity was expressed as the relative activity ratio of firefly luciferase to Renilla luciferase.

\section{Xenograft animal model}

Xenograft model was performed as described previously $[3,32,33]$. Male BALB/c nude mice at 4-6 weeks of age (18-22 g) were purchased from Vital River Laboratory Animal Technology Co., Ltd. (Beijing, china). $5 \times 106$ stable shRBM24/shRunx1t1-infected 253 J cells were harvested by trypsinization and resuspended in $0.2 \mathrm{~mL}$ PBS mixed with 50\% Matrigel (Collaborative Research Inc., Bedford, MA, USA); this suspension was injected subcutaneously into the right dorsal flanks. The length and width of mouse tumor were measured twice a week with calipers. 
Then we can use the formula to calculate tumor volume (volume $=[($ length $\times$ width2)/2]). At the end of this experiment, The mice were euthanized by Carbon dioxide asphyxiation. All animal studies were approved by the Institutional Animal Care and Use Committee of Hebei Medical University (approval ID: HebMU 20080026), and were made to minimize suffering.

\section{Morphometry and histology}

Human bladder cancer and normal bladder tissues were fixed with formalin solution and then processed for routine embedding in paraffin. Ten consecutive 5 - $\mu$ m-thick sections were prepared for hematoxylin and eosin staining. The cross-section Images were acquired using a Leica microscope (Leica DM6000B, Switzerland) and digitized with LAS V.4.4 (Leica).

\section{Immunofluorescence staining}

Five-micrometer paraffin-embedded cross-sections of tissues were subjected to immunofluorescence staining as described previously [33]. Sections were deparaffinized with xylene, rehydrated, and pre-incubated with $10 \%$ normal goat serum (710027, KPL, USA) followed by incubation with the following primary antibodies: antiRBM24 (18178-1-AP) and anti-Runx1t1 (67086-1-lg). Sections were subsequently treated with the following secondary antibodies: fluorescein-labeled antibody to rabbit IgG (021516; KPL, USA) and rhodamine-labeled antibody to mouse IgG (031806; KPL). In each experiment, DAPI (157574; MB Biomedical) was used for nuclear counterstaining. Images were captured using a confocal microscope (DM6000 CFS; Leica) and processed using LAS AF software.

\section{MTT assay}

Cell viability was detected by MTT [3-(4,5-dimethylthiazol-2-yl)-2,5-diphenyltetrazolium bromide] colorimetric assay. Briefly, 253J and J82 cells were plated in 96-well plates and treated with actinomycin (Act) for 0, 2, 4, and $8 \mathrm{~h}$ then $20 \mu \mathrm{L}$ of MTT reagent ( $5 \mathrm{mg} / \mathrm{mL}$; Sigma-Aldrich) was added into each well, incubated for $3-4 \mathrm{~h}$, and the absorbance was measured at $570 \mathrm{~nm}$ using a microplate reader (Thermo Fisher, USA).

\section{RNA immunoprecipitation (RIP) assays}

$253 \mathrm{~J}$ cells were transfected with pWPI or oeRBM24 for $48 \mathrm{~h}$, and then cells were used to conduct RIP experiments using a RBM24 antibody (18178-1-AP) or IgG, and the Dynabeads ${ }^{\text {TM }}$ Protein G Immunoprecipitation Kit (10007D, Thermo Fisher) according to the manufacturer's instructions. The RNA fraction isolated by RIP was quantified by NanoDrop 2000 (Thermo-Fisher). The cDNA was synthesized using a M-MLV First Strand Kit (Life Technologies) with random hexamer primers. The RIP' STAT3, GAPDH and Runx1t1 primers (Table 2) were subjected to qRT-PCR using the Platinum SYBR Green qPCR Super Mix UDG Kit (Invitrogen) and the ABI 7500 FAST system (Life Technologies).

\section{Chromatin immunoprecipitation (ChIP) assay}


The chromatin immunoprecipitation (ChIP) assay was performed as described previously[3]. In brief, 253J cells were treated with $1 \%$ formaldehyde for $10 \mathrm{~min}$ to cross-link proteins with DNA. The cross-linked chromatin was then prepared and sonicated to an average size of 400-600 bp. The samples were diluted 10-fold and then precleared with protein A-agarose/salmon sperm DNA for $30 \mathrm{~min}$ at $4{ }^{\circ} \mathrm{C}$. The DNA fragments were immunoprecipitated overnight at $4^{\circ} \mathrm{C}$ with anti-Runx1t1, or anti-TCF4 or anti-lgG (as negative control) antibodies. After cross-linking reversal, TCF4 and Runx1t1 occupancy on the miR-625 promoter was examined. Results were determined by qRT-PCR. ChIP primer sequences were summarized in Table 2.

\section{Target prediction}

TargetScan (http://www.targetscan.org/vert_72/), miRanda database (http://www.microrna.org/microrna/home.do) and RNA22 (http://cm.jefferson.edu/rna22/Interactive/) [34, 35] were performed to indentify the Potential microRNAs target to 3' UTR of RBM24.

\section{Statistical analysis}

Data were presented as the means \pm SEM. Student's t-test was used to analysis the differences between two groups for multiple comparisons or repeated measurements, ANOVA or repeated ANOVA followed by Tukey's post hoc test was used. $P<0.05$ was considered statistically significant. Statistical analysis was performed using Graphpad Prism 7 software (GraphPad Software).

\section{List Of Abbreviations}

\section{RBM24}

RNA binding motif protein 24;

ColP

Co-immunoprecipitation;

PLA

proximity ligation assay;

ChIP

Chromatin immunoprecipitation;

RIP

RNA immunoprecipitation;

BC

bladder cancer;

UTR

untranslated region;

TCF4

Transcription factor 4;

Runx1t1

Runt-related transcription factor 1 ;

\section{RBPs}

RNA-binding proteins; 
TCGA

The Cancer Genome Atlas;

\section{Declarations}

\section{Ethics approval and consent to participate}

The present study was authorized Ethics Committee Hebei Medical University. All patients and volunteers were anonymous and provided written informed consent.

\section{Consent for publication}

Written consent was obtained from all participants.

\section{Availability of data and materials}

Not applicable.

\section{Competing interests}

The authors declare that they have no competing interests.

\section{Funding}

Not applicable

\section{Authors' contributions}

Conception and design: Y.Y., K.L. and P.G.; Tissues collection: B.L., Y.N. and C.Z.; Development of methodology: Y.Y., B.L., J.C. and P.G.; Acquisition of the data: Y.Y., W.L. and K.L.; Analysis of data: W.L., Y.Y. and J.C.; Writing the manuscript: Y.Y., K.L. and J.C.

\section{Acknowledgements}

Not available.

\section{Conflict of interest:}

The authors declare that they have no conflict of interest.

\section{References}


1. Martinez Rodriguez RH, Buisan Rueda O, Ibarz L. Bladder cancer: Present and future. Med Clin (Barc). 2017;149(10):449-55.

2. Bhanvadia SK. Bladder Cancer Survivorship. Curr Urol Rep. 2018;19(12):111.

3. Zhang YP, Liu KL, Wang YX, Yang Z, Han ZW, Lu BS, Qi JC, Yin YW, Teng ZH, Chang XL, et al. Down-regulated RBM5 inhibits bladder cancer cell apoptosis by initiating an miR-432-5p/beta-catenin feedback loop. FASEB J. 2019;33(10):10973-85.

4. Dy GW, Gore JL, Forouzanfar MH, Naghavi M, Fitzmaurice C. Global Burden of Urologic Cancers, 1990-2013. Eur Urol. 2017;71(3):437-46.

5. Gaertner A, Brodehl A, Milting H. Screening for mutations in human cardiomyopathy- is RBM24 a new but rare disease gene? Protein cell. 2019;10(6):393-4.

6. Yang J, Hung LH, Licht T, Kostin S, Looso M, Khrameeva E, Bindereif A, Schneider A, Braun T. RBM24 is a major regulator of muscle-specific alternative splicing. Dev Cell. 2014;31(1):87-99.

7. Poon KL, Tan KT, Wei YY, Ng CP, Colman A, Korzh V, Xu XQ. RNA-binding protein RBM24 is required for sarcomere assembly and heart contractility. Cardiovasc Res. 2012;94(3):418-27.

8. Xu E, Zhang J, Zhang M, Jiang Y, Cho SJ, Chen X. RNA-binding protein RBM24 regulates p63 expression via mRNA stability. Mol Cancer Res. 2014;12(3):359-69.

9. Hua WF, Zhong Q, Xia TL, Chen Q, Zhang MY, Zhou AJ, Tu ZW, Qu C, Li MZ, Xia YF, et al. RBM24 suppresses cancer progression by upregulating miR-25 to target MALAT1 in nasopharyngeal carcinoma. Cell Death Dis. 2016;7(9):e2352.

10. Lin Y, Tan KT, Liu J, Kong X, Huang Z, Xu XQ. Global profiling of Rbm24 bound RNAs uncovers a multitasking RNA binding protein. Int J Biochem Cell Biol. 2018;94:10-21.

11. Amann JM, Nip J, Strom DK, Lutterbach B, Harada H, Lenny N, Downing JR, Meyers S, Hiebert SW. ETO, a target of $\mathrm{t}(8 ; 21)$ in acute leukemia, makes distinct contacts with multiple histone deacetylases and binds mSin3A through its oligomerization domain. Mol Cell Biol. 2001;21(19):6470-83.

12. Miyoshi H, Kozu T, Shimizu K, Enomoto K, Maseki N, Kaneko Y, Kamada N, Ohki M. The t(8;21) translocation in acute myeloid leukemia results in production of an AML1-MTG8 fusion transcript. EMBO J. 1993;12(7):2715-21.

13. Two-dose measles immunization recommendations. $N$ Y State J Med 1989, 89(8):492-493.

14. Cheng CC, Chang SJ, Chueh YN, Huang TS, Huang PH, Cheng SM, Tsai TN, Chen JW, Wang HW. Distinct angiogenesis roles and surface markers of early and late endothelial progenitor cells revealed by functional group analyses. BMC Genom. 2013;14:182.

15. Liao KH, Chang SJ, Chang HC, Chien CL, Huang TS, Feng TC, Lin WW, Shih CC, Yang MH, Yang SH, et al. Endothelial angiogenesis is directed by RUNX1T1-regulated VEGFA, BMP4 and TGF-beta2 expression. PLoS One. 2017;12(6):e0179758.

16. Alfayez M, Vishnubalaji R, Alajez NM. Runt-related Transcription Factor 1 (RUNX1T1) Suppresses Colorectal Cancer Cells Through Regulation of Cell Proliferation and Chemotherapeutic Drug Resistance. Anticancer Res. 2016;36(10):5257-63.

17. Bashanfer SAA, Saleem M, Heidenreich O, Moses EJ, Yusoff NM. Disruption of MAPK1 expression in the ERK signalling pathway and the RUNX1RUNX1T1 fusion gene attenuate the differentiation and proliferation and induces the growth arrest in t(8;21) leukaemia cells. Oncol Rep. 2019;41(3):2027-40. 
18. Baby N, Li Y, Ling EA, Lu J, Dheen ST. Runx1t1 (Runt-related transcription factor 1; translocated to, 1) epigenetically regulates the proliferation and nitric oxide production of microglia. PLoS One.

2014;9(2):e89326.

19. Liu J, Kong X, Zhang M, Yang X, Xu X. RNA binding protein 24 deletion disrupts global alternative splicing and causes dilated cardiomyopathy. Protein Cell. 2019;10(6):405-16.

20. Rossetti S, Hoogeveen AT, Sacchi N. The MTG proteins: chromatin repression players with a passion for networking. Genomics. 2004;84(1):1-9.

21. Davis JN, McGhee L, Meyers S. The ETO (MTG8) gene family. Gene. 2003;303:1-10.

22. Oliveira C, Faoro H, Alves LR, Goldenberg S. RNA-binding proteins and their role in the regulation of gene expression in Trypanosoma cruzi and Saccharomyces cerevisiae. Genet Mol Biol. 2017;40(1):22-30.

23. Glisovic T, Bachorik JL, Yong J, Dreyfuss G. RNA-binding proteins and post-transcriptional gene regulation. FEBS Lett. 2008;582(14):1977-86.

24. Zhang T, Lin Y, Liu J, Zhang ZG, Fu W, Guo LY, Pan L, Kong X, Zhang MK, Lu YH, et al. Rbm24 Regulates Alternative Splicing Switch in Embryonic Stem Cell Cardiac Lineage Differentiation. Stem Cells. 2016;34(7):1776-89.

25. Mukherjee N, Wessels HH, Lebedeva S, Sajek M, Ghanbari M, Garzia A, Munteanu A, Yusuf D, Farazi T, Hoell $\mathrm{Jl}$, et al. Deciphering human ribonucleoprotein regulatory networks. Nucleic Acids Res. 2019;47(2):570-81.

26. Khund-Sayeed S, He X, Holzberg T, Wang J, Rajagopal D, Upadhyay S, Durell SR, Mukherjee S, Weirauch MT, Rose R, et al. 5-Hydroxymethylcytosine in E-box motifs ACAT|GTG and ACAC|GTG increases DNA-binding of the B-HLH transcription factor TCF4. Integr Biol (Camb). 2016;8(9):936-45.

27. Bayly R, Chuen L, Currie RA, Hyndman BD, Casselman R, Blobel GA, LeBrun DP. E2A-PBX1 interacts directly with the KIX domain of CBP/p300 in the induction of proliferation in primary hematopoietic cells. J Biol Chem. 2004;279(53):55362-71.

28. Patel J, Baranwal S, Love IM, Patel NJ, Grossman SR, Patel BB. Inhibition of C-terminal binding protein attenuates transcription factor 4 signaling to selectively target colon cancer stem cells. Cell Cycle. 2014;13(22):3506-18.

29. Ruiz de Garibay G, Mateo F, Stradella A, Valdes-Mas R, Palomero L, Serra-Musach J, Puente DA, Diaz-Navarro A, Vargas-Parra G, Tornero E, et al: Tumor xenograft modeling identifies an association between TCF4 loss and breast cancer chemoresistance. Dis Model Mech 2018, 11(5).

30. in 't Hout FE. van der Reijden BA, Monteferrario D, Jansen JH, Huls G. High expression of transcription factor 4 (TCF4) is an independent adverse prognostic factor in acute myeloid leukemia that could guide treatment decisions. Haematologica 2014, 99(12):e257-9.

31. Liu Y, Wang JX, Nie ZY, Wen Y, Jia XJ, Zhang LN, Duan HJ, Shi YH. Upregulation of ERp57 promotes clear cell renal cell carcinoma progression by initiating a STAT3/ILF3 feedback loop. J Exp Clin Cancer Res. 2019;38(1):439.

32. Yang Z, Chen JS, Wen JK, Gao HT, Zheng B, Qu CB, Liu KL, Zhang ML, Gu JF, Li JD, et al. Silencing of miR193a-5p increases the chemosensitivity of prostate cancer cells to docetaxel. J Exp Clin Cancer Res. 2017;36(1):178.

33. Yang Z, Qu CB, Zhang Y, Zhang WF, Wang DD, Gao CC, Ma L, Chen JS, Liu KL, Zheng B, et al. Dysregulation of p53-RBM25-mediated circAMOTL1L biogenesis contributes to prostate cancer progression through the 
circAMOTL1L-miR-193a-5p-Pcdha pathway. Oncogene. 2019;38(14):2516-32.

34. Lewis BP, Burge CB, Bartel DP. Conserved seed pairing, often flanked by adenosines, indicates that thousands of human genes are microRNA targets. Cell. 2005;120(1):15-20.

35. Betel D, Koppal A, Agius P, Sander C, Leslie C. Comprehensive modeling of microRNA targets predicts functional non-conserved and non-canonical sites. Genome biology. 2010;11(8):R90.

\section{Figures}

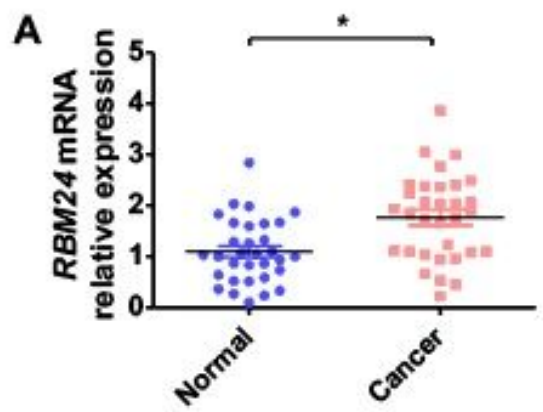

\section{B}

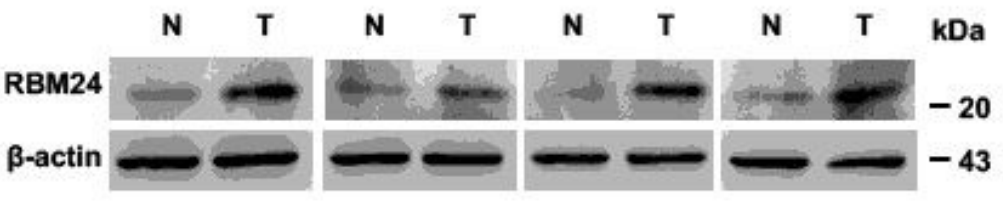

C
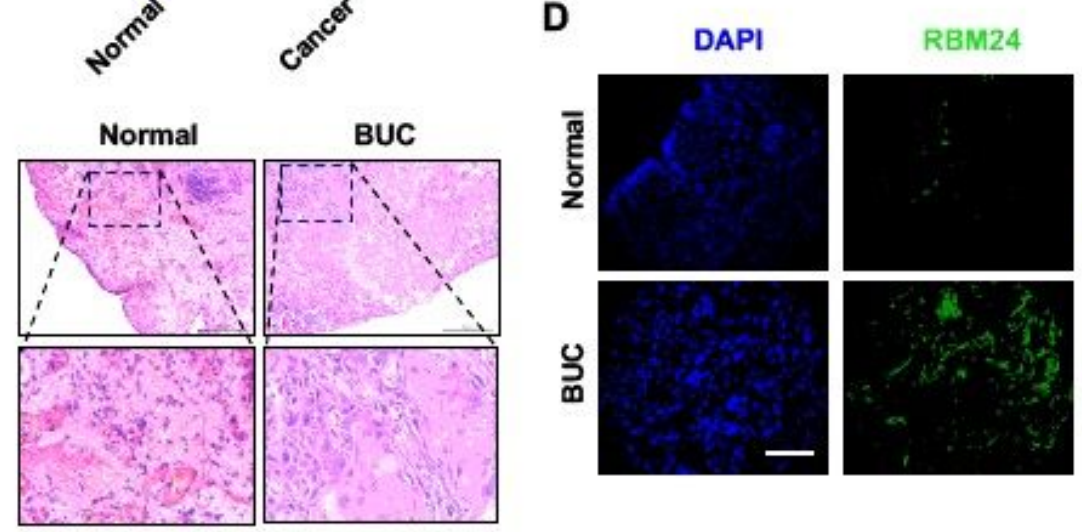

Merge
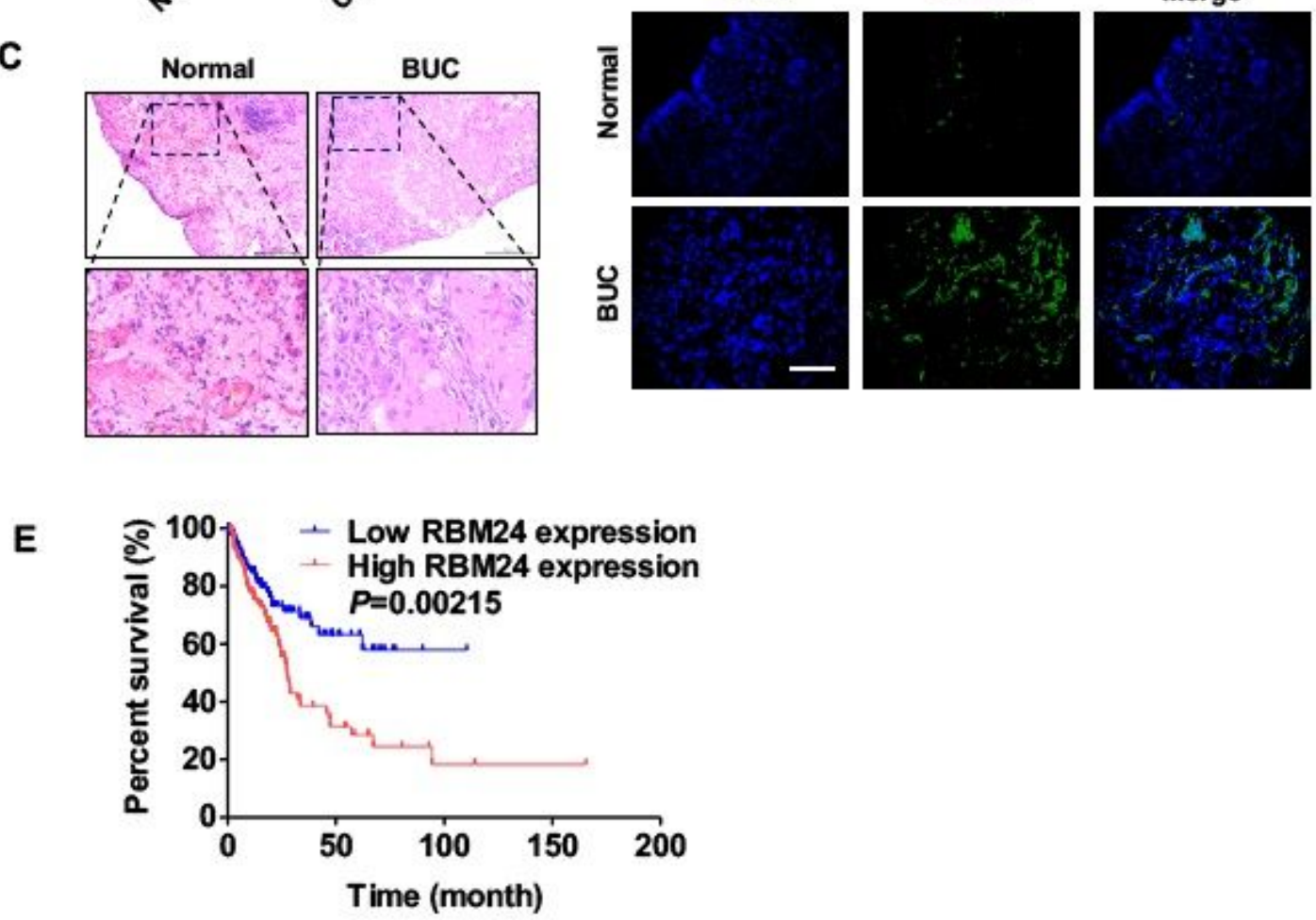

Figure 1

RBM24 is upregulated in BC tissues and contributes to poor prognosis. (A) RT-qPCR was used to detect the expression level of RBM24 in 62 pairs of BC tissues and normal bladder tissues. ${ }^{*} P<0.05$ vs. normal bladder tissues. (B) Western blot analysis examined the RBM24 protein level in four pairs of randomly selected tumor (T) and normal bladder tissues (N). (C) Hematoxylin and eosin staining of normal bladder and BC tissue. (D) Immunofluorescence staining of RBM24 in normal bladder tissues and BC tissues. Scale bar $=50 \mu \mathrm{m}$. (E) Kaplan-Meier analysis was used to analyze the overall survival of BC patients with low $(n=130)$ or high RBM24 $(n=130)$ level from TCGA database (cutoff value is $25 \%$ ). 


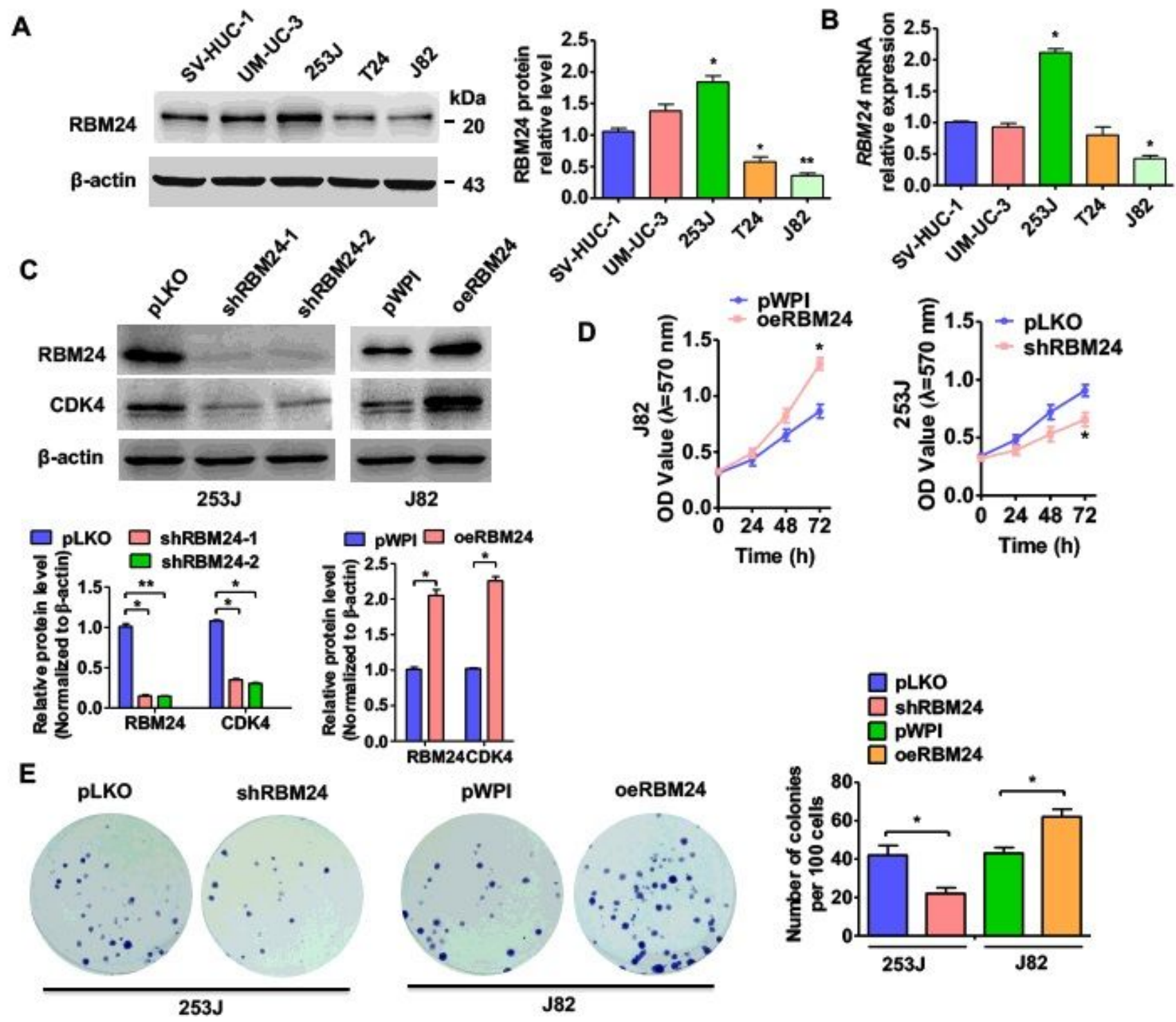

Figure 2

RBM24 promotes the proliferation of BC cells in vitro. (A) Western blot analysis was used to examine the protein level of RBM24 in human uroepithelial cells (SV-HUC-1) and BC cell lines (UM-UC-3, 253J,T24 and J82). The densitometric analysis (A) in three independent experiments. ${ }^{*} P<0.05$, ${ }^{\star}{ }^{2} P<0.01$ vs. SV-HUC-1. (B) RT-qPCR detected the expression of RBM24 mRNA in the cell lines. ${ }^{*} \mathrm{P}<0.05$ vs. SV-HUC-1. (C),RBM24 and CDK4 protein levels were measured by western blot analysis in shRBM24-transfected 253J cells or RBM24 overexpression vector (oeRBM24)-transfected J82 cells. ${ }^{*} \mathrm{P}<0.05$, ${ }^{\star *} \mathrm{P}<0.01$ vs. corresponding control. (D) Cells were prepared as (C), cell viability was measured by MTT assay. ${ }^{*} \mathrm{P}<0.05$ vs corresponding control. (E) Cells were prepared as (C), cell viability was measured by colony formation assays. Right panel shows the number of colony formation. *P<0.05 vs corresponding control. 


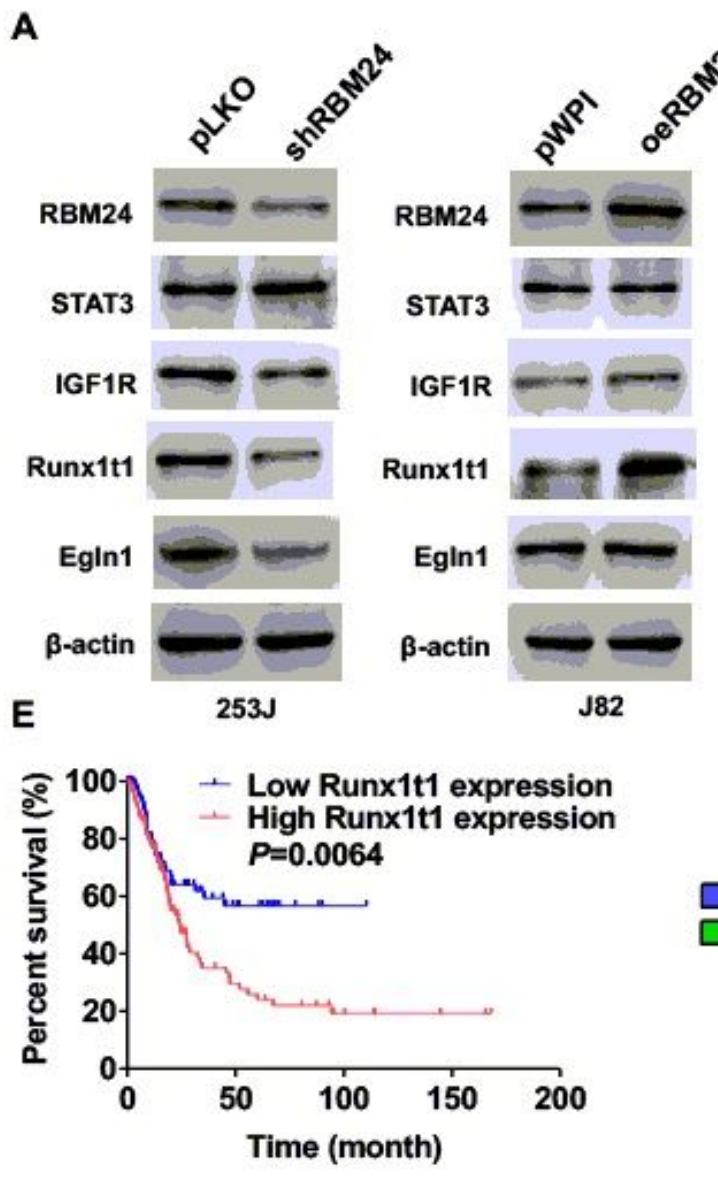

G

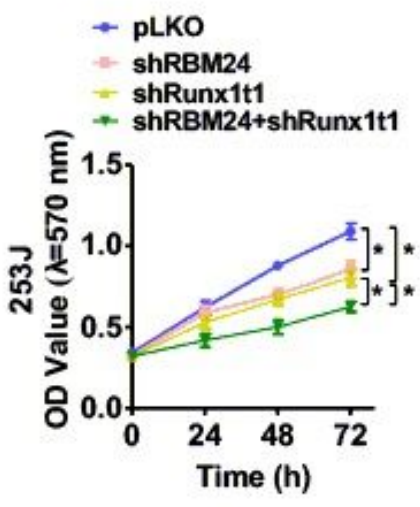

B

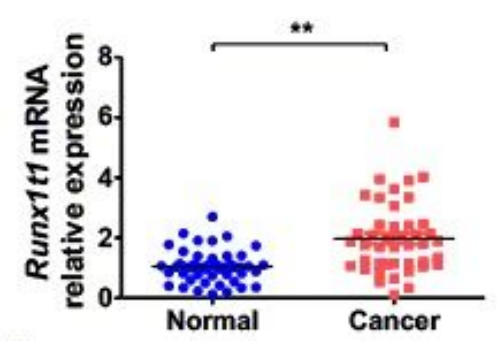

F

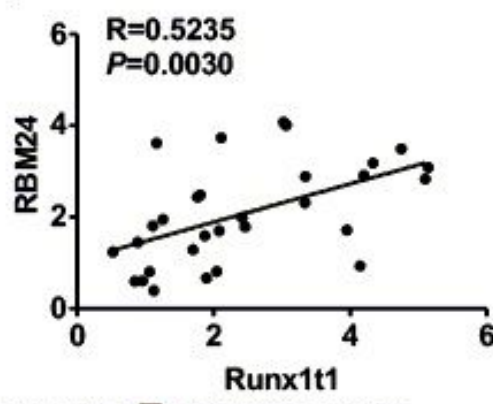

$\square$ pLKO + pWPI $\square$ shRunx1t1 + pWPI

$\square$ pLKO + oeRBM24 $\square$ shRunx1t1 + shE2F5

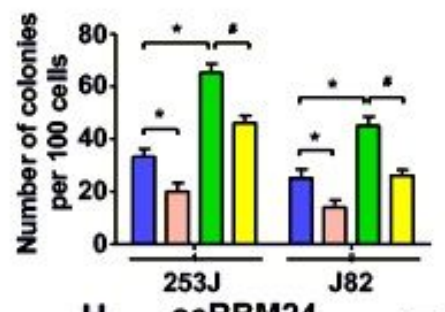

H
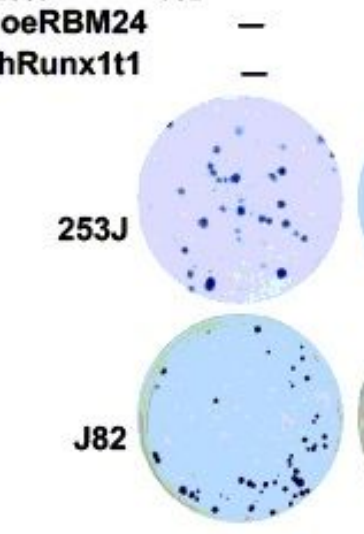

C

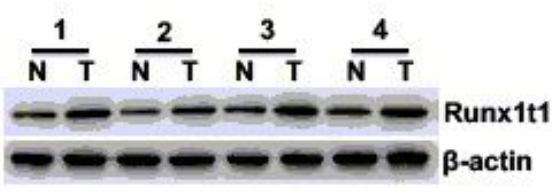

D
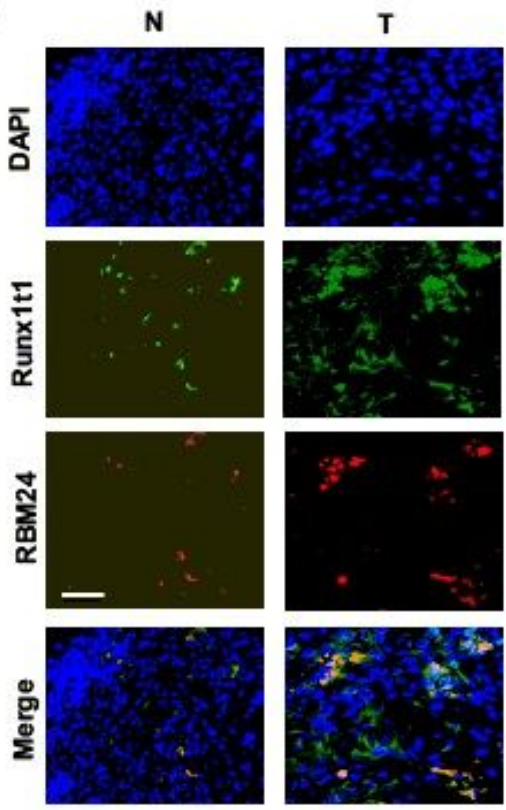

\section{Figure 3}

Runx1t1 mediates the RBM24-induced cell proliferation. (A) 253J cell was transfected with shRBM24 vector or J82 was transfected with with oeRBM24. Western blot was used to detect the protein expression with indicated antibody. (B) RT-qPCR detected the Runx1t1 mRNA expression in 62 pairs of BC tissues and normal bladder tissues. ${ }^{*} \mathrm{P}<0.01$ vs. normal bladder tissues. (C) Runx1t1 protein level was measured by western blot in four pairs of randomly selected tumor $(T)$ and normal bladder tissues $(N)$. (D) Immunofluorescence staining of RBM24 (red) and Runx1t1 (green) in normal bladder $(\mathrm{N})$ and BC tissue $(\mathrm{T})$. Scale bar = $50 \mu \mathrm{m}$. (E) Kaplan-Meier analysis was used to analyze the overall survival of $\mathrm{BC}$ patients with low or high Runx1t1 level from TCGA database. (F) Pearson's correlation revealed a positive correlation between RBM24 and Runx1t1 mRNAs in BC tissues $(R=05235 ; P=0.0030) .(G), 253 \mathrm{~J}$ and $\mathrm{J} 82$ cells transfected with indicated vectors and cell viability was 
measured by MTT assay. ${ }^{*} \mathrm{P}<0.05$ vs corresponding control $(\mathrm{H})$ Cells were prepared as $(\mathrm{G})$, cell viability was measured by colony formation assays. Above panel shows the number of colony formation. * $\mathrm{P}<0.05$ vs corresponding control.

A

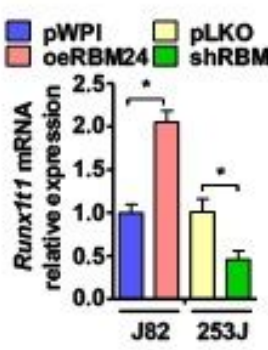

B

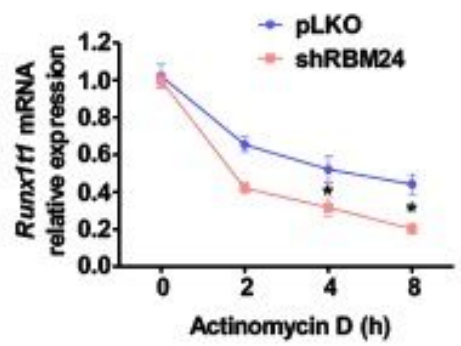

Actinomycin D (h)

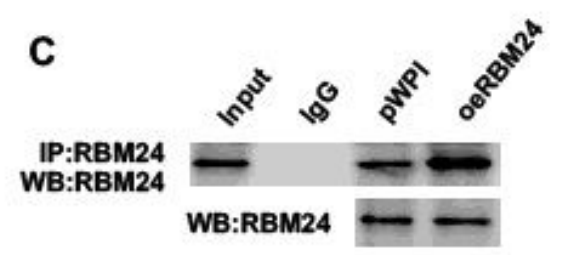

F

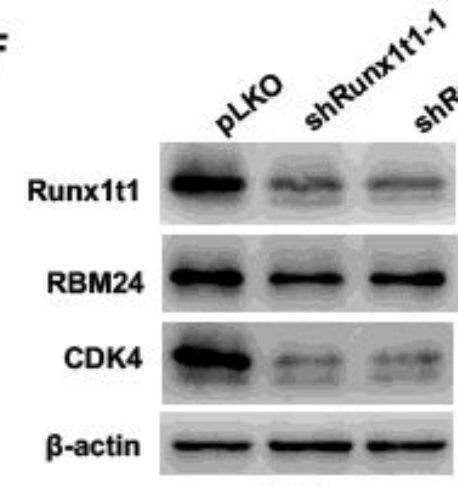

253J
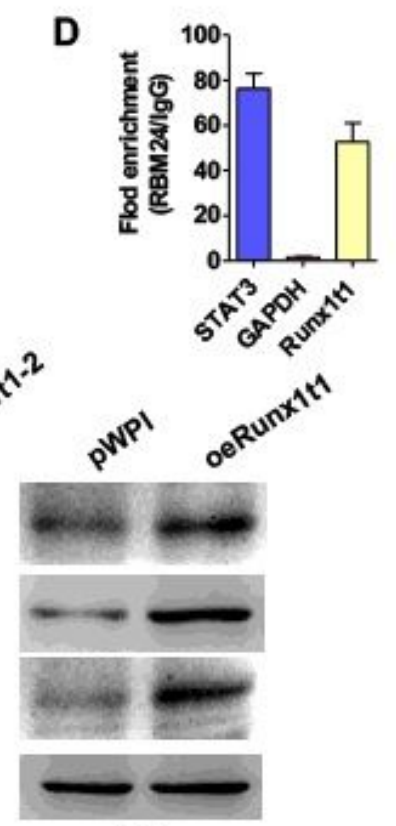

J82

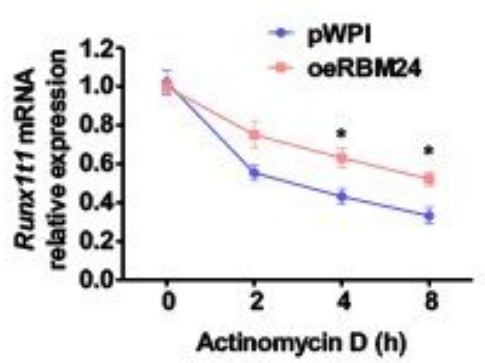

E

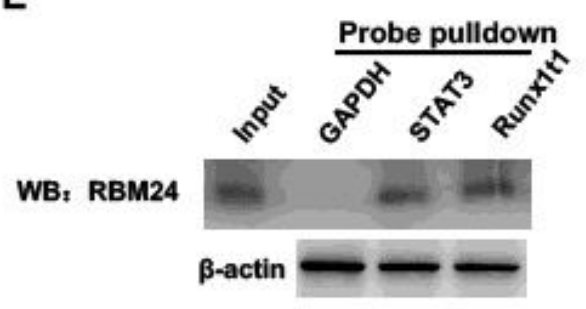

G

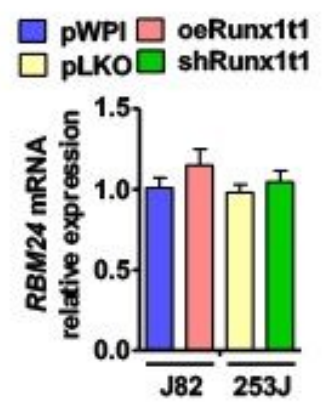

Figure 4

RBM24 promotes Runx1t1 expression by stabilizing its mRNA. (A) J82 cells transfected with RBM24 overexpression vector pWP-RBM24 or 253J cell transfected with shRBM24. The expression of Runx1t1 mRNA was measured by RT-qPCR. * $\mathrm{P}<0.05$ vs. corresponding control. (B) Cells were treatment as $(A)$ and then exposed to Actinomycin $D$ for $0,2,4$, and $8 \mathrm{~h}$. The expression of Runx $1 \mathrm{t} 1 \mathrm{mRNA}$ was detected by using $\mathrm{qRT}-\mathrm{PCR}$. ${ }^{*} \mathrm{P}<0.05$, vs. corresponding control. (C) 253J cells were transfected with pWPI-RBM24 or empty vector. Western blot was used to measure the precipitation efficiency of RBM24 antibody. (D) RNA binding protein immunoprecipitation (RIP) PCR was used to test the interaction between RBM24 protein and Runx1t1 mRNA. (E) Different probes were used to oligo-pulldown and western blot analysis was used to test the RBM24 in pulldown precipitate. (F) 253J cells were transfected with sh Runx1t1 or J82 cells transfected with pWP-Runx1t1. Western blot analysis was used to detect the protein levels of Runx1t1, RBM24 and CDK4. (G) Cells were prepared as (F), RT-qPCR was used to detect the RBM24 mRNA expression. 
A

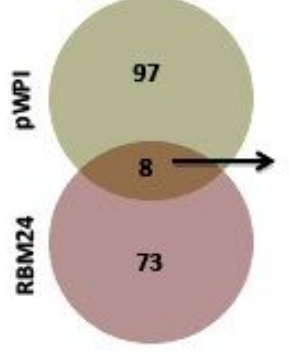

D

G

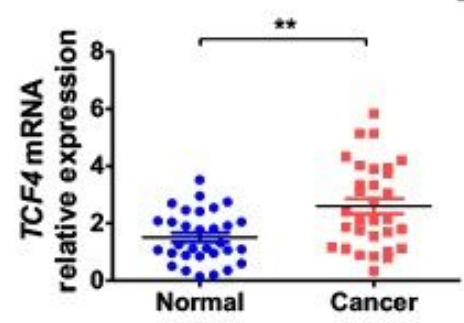

B

\begin{tabular}{lc}
\hline Protein & $\begin{array}{l}\text { FC Rank } \\
\text { Runx1t1 Co- } \\
\text { IP }\end{array}$ \\
\hline PLA2G4A & 1 \\
SON & 2 \\
TCF4 & 3 \\
ID1 & 4 \\
SPI1 & 5 \\
FOSB & 6 \\
TCF12 & 7 \\
ZBTB16 & 8 \\
\hline
\end{tabular}

E

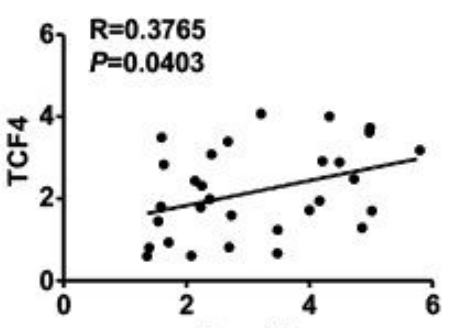

C

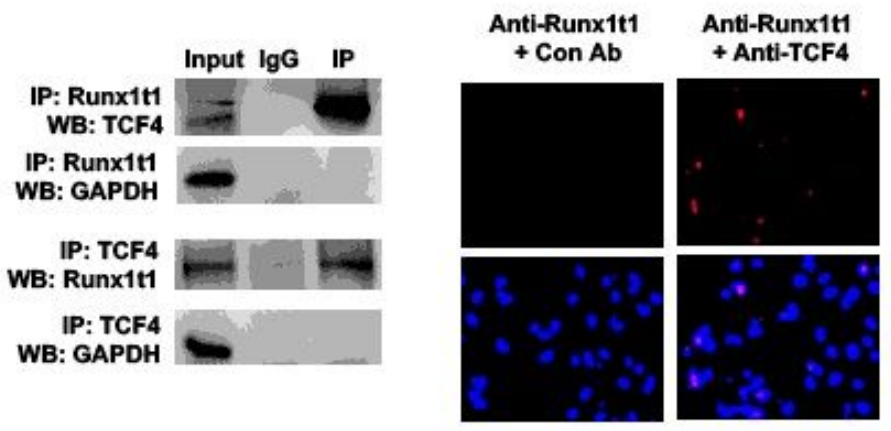

$\mathbf{F}$

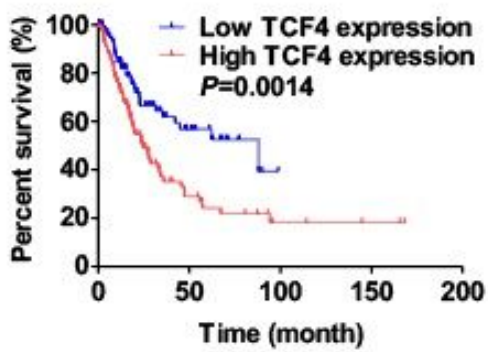

H

pWPI $+-+-\quad$ pLKO

$\underset{\text { PLKO }}{+}+\overline{+}$

oeRunx1t1 $-\overline{+}+$

shRunx1t1 $-\quad++$

TCF4

Runx1t1

CDK4

RBM24

$\beta$-actin

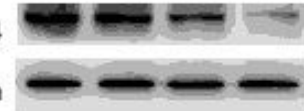

pLKO ++-

ShTCF4 -++

TCF4

Runx1t1

CDK4

RBM24

$\beta$-actin
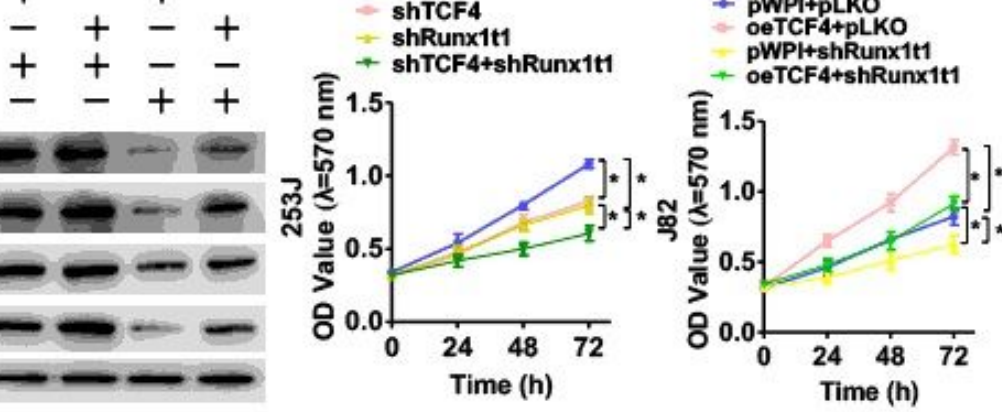

253.

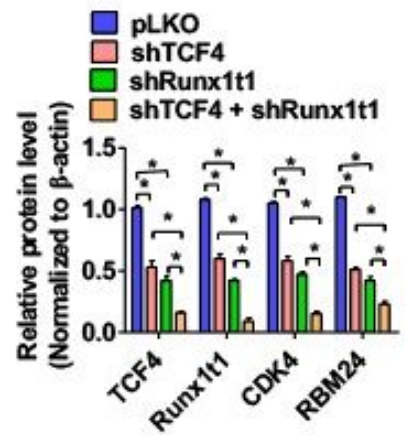

口 PWPI + pLKO

J82

oeRunx1t1 + pLKO

pWPI + shTCF4

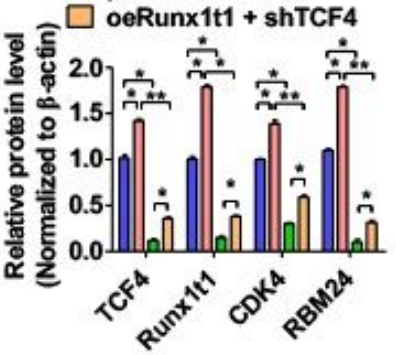

$\mathbf{J}$
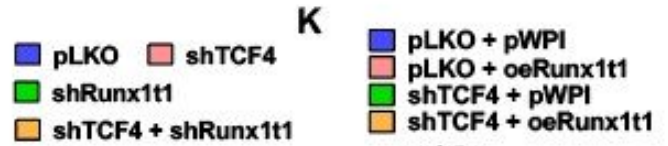

1.5
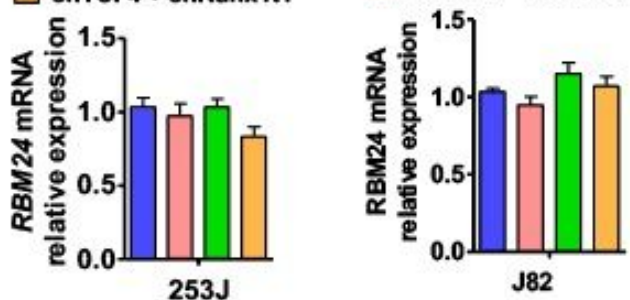

Figure 5

Runx1t1 interacts with transcription factor TCF4 to mediate RBM24 upregulation and cell proliferation. (A) Coimmunoprecipitation coupled with mass spectrometry (CoIP-MS) was performed with an anti-Runx1t1 in J82 cells to detect the proteins interacting with Runx1t1 change after RBM24-overexpressed. The right table showed 8 proteins interaction increased with Runx1t1. (B) ColP analysis was used to detect the interaction between TCF4 and Runx1t1, and GAPDH was used as a negative control. (C) In situ proximity ligation analysis (PLA) detected the interaction between TCF4 and Runx1t1. Red color indicates PLA-positive cells. (D) RT-qPCR examined the expression of TCF4 in BC tissues and normal bladder tissues. ${ }^{*} \mathrm{P}<0.01$ vs. normal bladder tissues. (E) Pearson's correlation analyzed correlation between TCF4 and Runx1t1 mRNAs in BC tissues $(R=0.3765 ; P=0.0403)$. ( $F$ ) 
Kaplan-Meier analysis was used to analyze the overall survival of BC patients with low or high TCF4 level from TCGA database. $\mathrm{P}=0.0014 . \mathrm{G}$ and $\mathrm{H}$, Western blot analysis examined the TCF4, Runx1t1, CDK4 and RBM24 expression in 253J cells transfected with shTCF4 and shRunx1t1 either alone or together (G), or J82 cells transfected with oeRunx1t1 and shTCF4 either alone or together $(\mathrm{H})$. Button panel shown densitometric analysis in three independent experiments. ${ }^{\star} \mathrm{P}<0.05,{ }^{\star} \mathrm{P}<0.01 \mathrm{vs}$. corresponding control. (I) Cells were prepared as ( $\mathrm{G}$ and $H)$, cell viability was measured by MTT assay. ${ }^{*} P<0.05$ vs. corresponding control. (J) Cells were prepared as (G and $\mathrm{H}$ ), RT-qPCR was used to detect the expression of RBM24 mRNA.

A

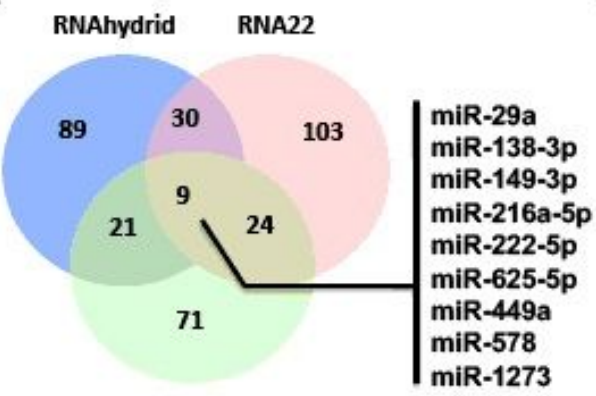

miRanda

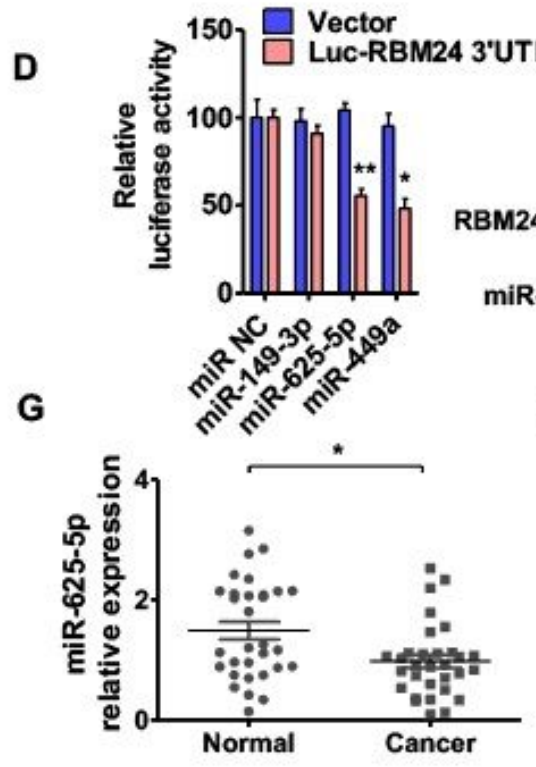

$J$

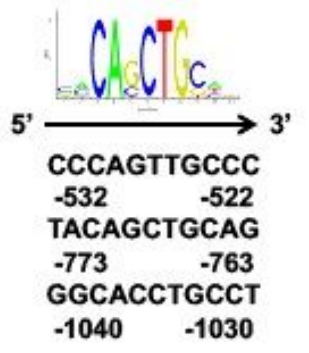

$\mathbf{K}$
B

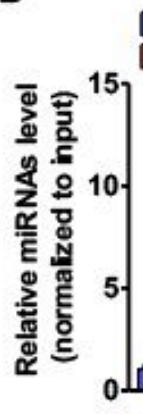

Control RBM24 3' UTR

Biotin-labeled RBM24 3' UTR

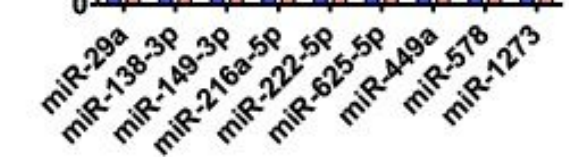

E

GAATTGTTTTCTCTTTCCCTCC

$|:|:|\quad|||||||: \mid$

CCTGATA-TCTTGAAAGGGGA

H
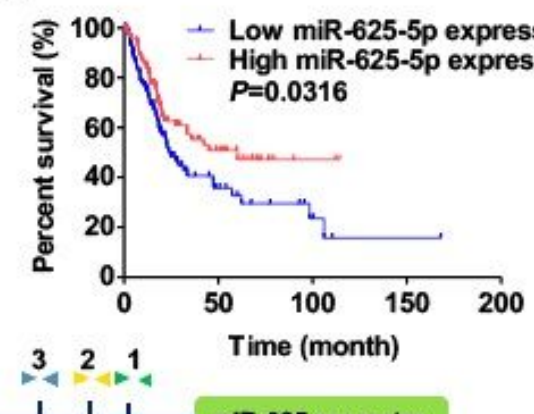

miR-625 promoter

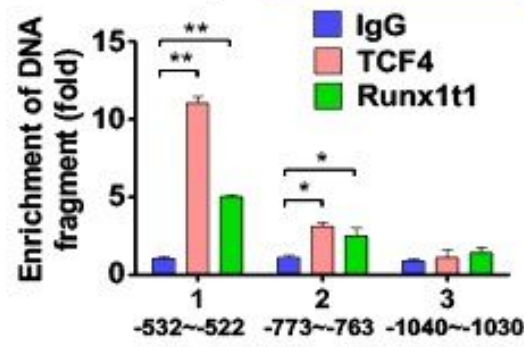

$\mathbf{L}$
C $\square$ pWPI + pLKO $\square$ oeRUNX1T1 + pLKO $\square$ pWPI + shTCF $\square$ oeRUNX1T1 + shTCF4
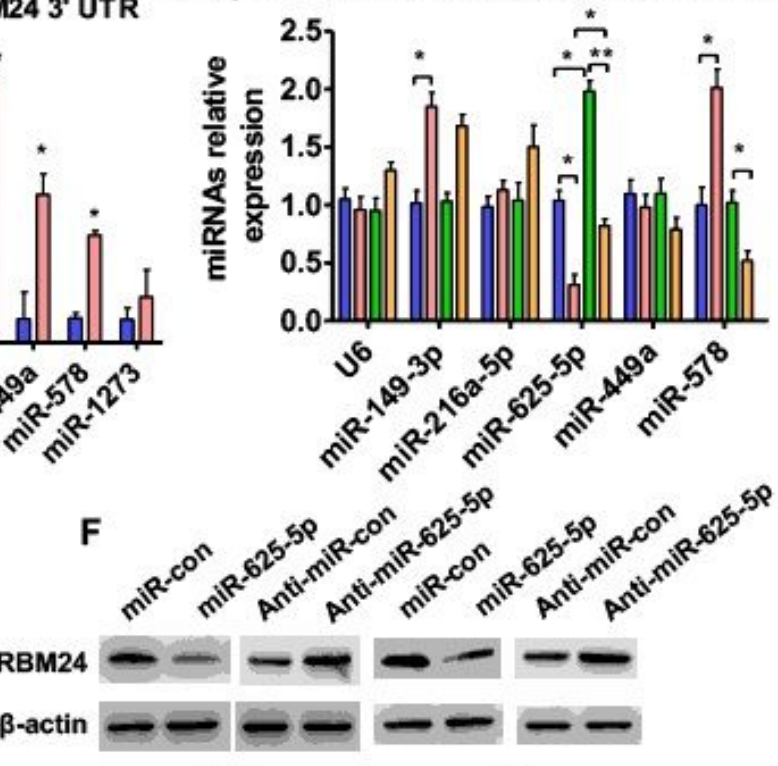

253J

J82
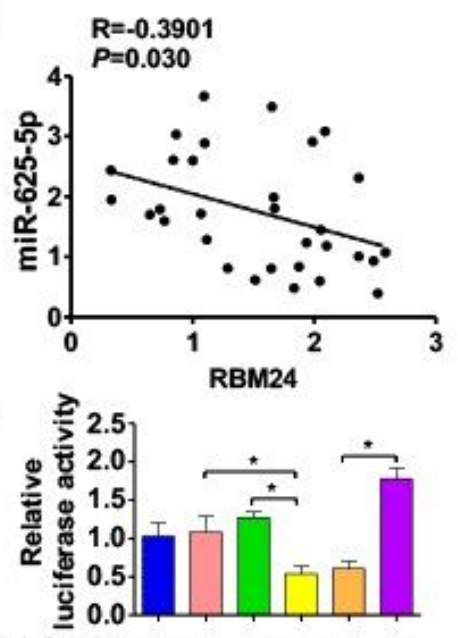

pGL3-Basic + + - - -

PGL3-miR-625-LUC -+++++ pWPI +-+--

oeRBM24 - + - + +

pLKO - - - + -

shTCF4 - - - - +

Figure 6

miR-625-5p mediates Runx1t1/TCF4-regulated proliferation by direct targeting in BC cells . (A) Venn diagram displaying potential microRNAs associated with RBM24 3'UTR sequence from three online target-prediction 
programs. (B) Biotin-labeled RBM24 3'-UTR RNA was transfected into J82 cells followed by a biotin pull-down assay using Streptavidin-coupled Dynabeads. The miRNAs were extracted from the sedimented beads, and the relative levels of 9 candidate miRNAs were detected by RT-qPCR. ${ }^{*} P<0.05,{ }^{*} \mathrm{P}<0.01 \mathrm{vs}$. control probe. (C) J82 cell was transfected with oeRunx1t1 or shTCF4 or co-transfected with both vectors together. RT-qPCR was used to detect the expression of 5 miRNAs. ${ }^{*} P<0.05, * \star P<0.01$ vs. their corresponding controls. (D) J82 cell was cotransfected with RBM24 3'UTR and indicated miRNAs mimic. Luciferase reporter assays was showed miR-625-5p and miR-449a reduced the RBM24 3'UTR luciferase activity. ${ }^{\star} \mathrm{P}<0.05$, ${ }^{\star *} \mathrm{P}<0.01$ vs. control vector. (E) Prediction of miR-625-5p binding site in RBM24 3'UTR. (F) 253J and J82 cells were transfected with indicated miRNAs and then western blot detected the RBM24 protein expression. (G) RT-qPCR detected the expression of miR-625-5p in $B C$ tissues or normal bladder tissues. ${ }^{*} P<0.05$ vs. normal bladder tissues. $(H)$ Kaplan-Meier analysis was used to analyze the overall survival of BC patients with miR-625-5p level from TCGA database. $P=0.0316$. (I) Pearson's correlation analyzed correlation between RBM24 and miR-625-5p expresion in BC tissues $(R=-0.3901$; $P=0.0030)$. ( $\mathrm{J}$ ) Potential binding site of TCF4 in miR-625 promoter. (K) ChIP-qPCR was used to test TCF4 and Runx1t1 complex binding to the miR-625 promoter region in $293 \mathrm{~A}$ cells. ${ }^{*} \mathrm{P}<0.05,{ }^{\star} * \mathrm{P}<0.01 \mathrm{vs}$. IgG. (L) miR-625 promoter-luciferase reporter was co-transfected with RBM24 overexpression vector or co-transfected with shTCF4 vector into $293 \mathrm{~A}$ cells. Luciferase reporter assays were performed the luciferase activity. ${ }^{*} \mathrm{P}<0.05$ vs. corresponding control.

A

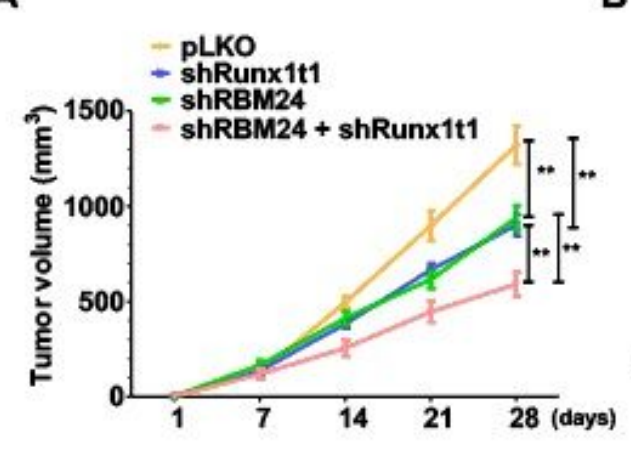

B

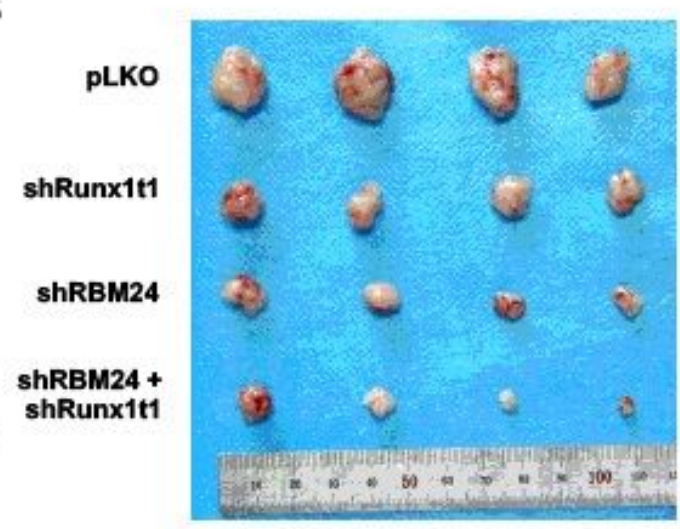

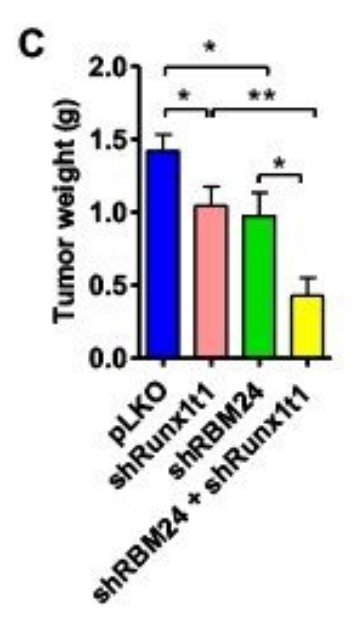
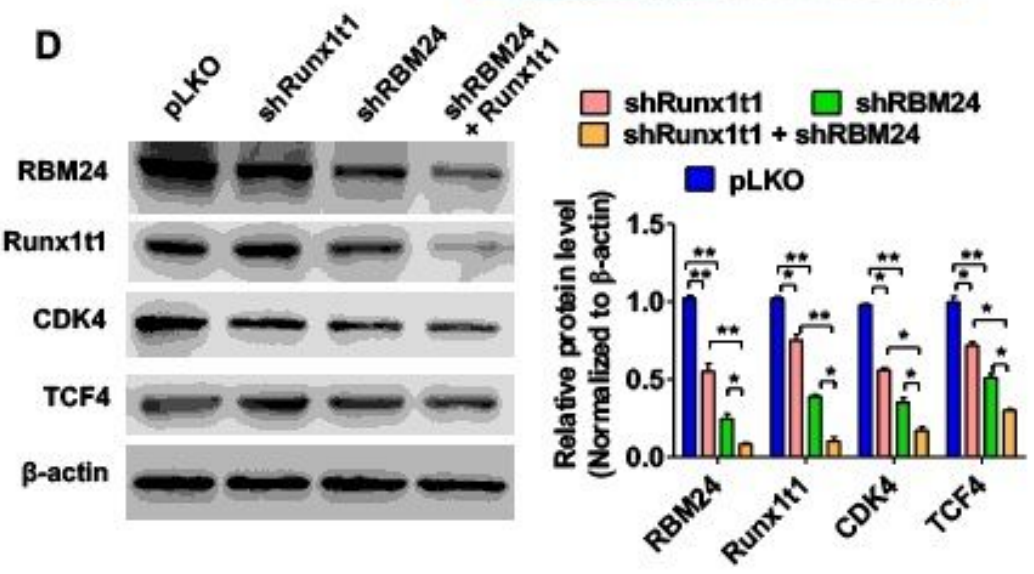

Figure 7

Disruption of the RBM24/Runx1t1/TCF4/miR-625-5p axis inhibits BC xenograft growth in vivo. (A) 253J cells stably depleted RBM24 or Runx1t1 or both together then the cells were injected subcutaneously to the nude mice to establish BC xenograft tumors. Tumor volumes were monitored by direct measurement. * $P<0.05$, ** $P<0.01$ vs. 
corresponding control. (B) Representative tumor sizes in each group of mice. (C) Xenograft tumor wet weight in each group of mice. ${ }^{*}<<0.05,{ }^{*} P<0.01$ vs. corresponding control. $D$, Western blot analysis was used to measure the protein levels of RBM24, Runx1t1, CDK4 and TCF4 in xenograft tumor.

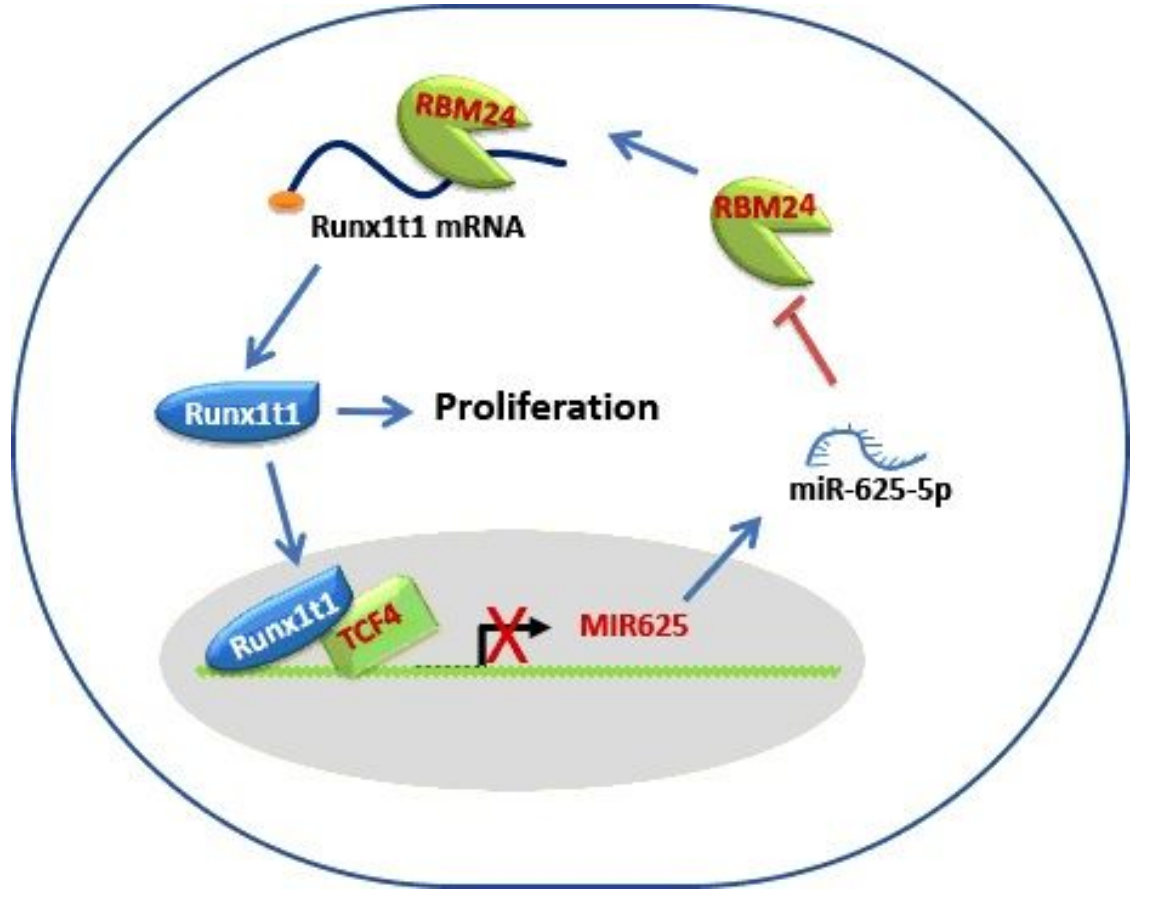

Figure 8

Proposed model for RBM24/Runx1t1/TCF4/miR-625-5p in BC feedback loop in regulating BC progression. 